\title{
Ancient Tax Tokens, Trade Licenses and Metrological Records?: Making Sense of Indus Inscribed Objects Through Script- Internal, Contextual, Linguistic, and Ethnohistorical Lenses.
}

\author{
Author: Bahata Ansumali Mukhopadhyay
}

\section{Abstract}

This article argues that most of the inscribed objects (seals, miniature-tablets etc.) of ancient Indus valley civilization were essentially administrative-commercial tools (tax-tokens, tradelicences, metrological records, etc.) used for controlling the complex trading economy spread across the Indus settlements. It also argues that the inscriptions logographically encoded a commercial sublanguage to convey information about kinds of taxes/tithes, tax-receiving entities; tax-rates and modes; and activities (such as cultivation, manufacture, and trading of specific commodities) that these taxes covered and authorized. Building on the functional classification of Indus logograms performed in the author's previous structural analysis of Indus inscriptions and analysing various script-internal, archaeological, historical and linguistic evidence, this article seeks to interpret the semantic functionalities of different sign-classes. It proposes that: i) The numerical and metrological signs were used to represent certain taxcollection rates fixed for certain commodities, whereas the lexeme-signs following them ( \& III, \& IIII, 这 III ) represented those taxed commodities. ii) The Crop-signs ( represented different harvested grain-based taxes. iii) The phrase-final/terminal logograms ( U, 个, 白, $8 \wedge 8,8 \wedge 8,8 \wedge$ ) encoded certain metrological modes (volumetric, weight-based, reedmeasure-based etc.) of tax-collection, and thus metonymically encoded certain broad taxcategories. iv) The lexeme-signs appearing in the initial parts of the grammatically complex inscriptions $(\hat{\nabla}, \otimes, \rho, \mathbb{W}$ ) represented the tax-collector entities and purpose of tax-payment. v) The signs mostly occurring in pre-phrase-final positions ( $U^{\Psi}, \Psi^{\Psi}, \mathcal{P}$, etc. $)$ represented the mode of tax-payments through predefined equivalencies. vi) The bird-like logograms (

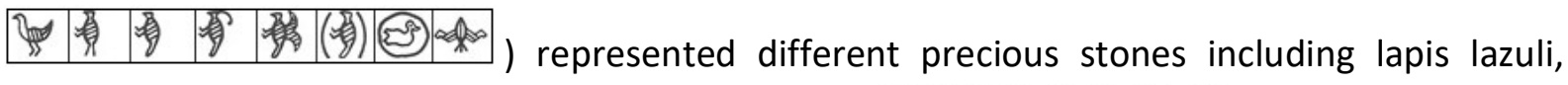

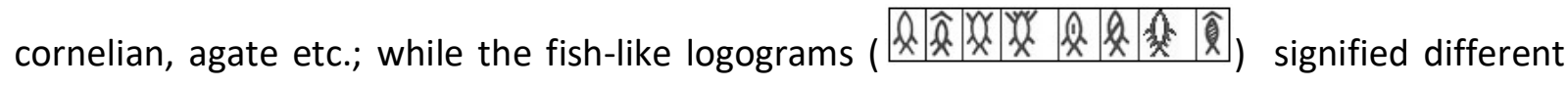
apotropaic "fish-eye-beads", which were one of the most precious exported Indus commodities, coveted in ancient Near East. Analysing the related lexical roots of such commodities - e.g. ivory ("piru"); lapis lazuli whose colour was compared to the iridescent pigeon-neck ("kāsaka hya kapautaka"); and "eye-beads" (maṇi), in Mesopotamian lexicons, Amarna letters, ancient texts in 
Old-Persian language, BMAC languages, Sanskrit, Pali, Tamil etc. - this study claims that such words had originated in the Indus valley, and had spread to the languages of other civilizations through trade networks. Tracing out more such ancient metrological and revenue related terminologies (droṇa, bhāra, kṛṣnala, raktikā, śara etc.) this study finally offers decipherment of a few Indus inscriptions.

\section{Introduction}

Indus inscriptions are embodied in nearly 4000 inscribed objects, mostly comprising inscribed seals, sealings (seal-impressions), tablets, amulets, ivory/bone rods and pottery vessels containing graffiti work (see the schematic diagrams in Fig. 1). These objects are excavated from various locations of the Indus valley civilization (henceforth IVC), that spanned around 800,000 square kilometres and had over 1500 settlements (Kenoyer, 2010) at its peak period (c. 26001900 BCE). Decoding of the messages conveyed by the inscriptions should make a major impact on our understanding of the ancient culture prevalent in the Indo-Pakistani subcontinent. However, the fact that most of the Indus inscriptions are written very briefly (c. $74 \%$ of the distinct inscription-lines contain only 1 to 5 signs), and that the script(s) used in the inscriptions is/are completely unknown makes the decipherment of the inscriptions a difficult task. Additionally, as the vast area covered by IVC continues to be a multi-linguistic region since the ancient times, it is hard to predict the underlying language of the inscriptions (even if the linguistic nature of the inscriptions gets established).

Ever since the first publication of an inscribed Indus seal in 1875, Indus script has received several theories and more than 60 claimed decipherments (Wells, 2011). Most of the Indus scholars agree on certain structural aspects of the script, including: the direction of writing used in the inscriptions; homologous usage patterns of certain initial and terminal signs present in the inscriptions; existence of certain numerical notations in the inscriptions; and certain generally adopted inscription-segmentation techniques (Mahadevan, 1986). Although the extensive scholarly researches have provided several significant insights about Indus inscriptions, none of the claimed decipherments have achieved appreciable consensus. The dissensus ranges from opinions that Indus inscriptions were written logo-syllabically (Parpola A, 1994: 85; Wells, 2015: 32,85 ) or logographically (Mahadevan, 1986) to the idea that "Indus inscriptions did not encode speech" at all (Farmer, Sproat, and Witzel, 2004). The underlying language of the script is argued to be Dravidian by some scholars (Mahadevan, 2014; Parpola A., 1994: 274), and linked to IndoAryan languages by some others (Rao, 1982). The meanings of the inscriptions and the functionality of most of the signs are also fiercely debated. For example, the most frequent fish-

like sign $\&$ is classified as a syllabic sign by Wells (2015:7), an attributive-lexeme by Mahadevan (1986:21), and a metrological unit by Bonta (2010: 57). Parpola (1994:179-185,279-283) suggests 
that might have represented the Dravidian word "mīn" which meant "fish", "star" and "to shine or glitter" and was part of certain theophoric astral names used in IVC. These completely contradictory interpretations about sign $\ell$ representatively reflect the extent of controversies associated to the other signs.

Figure 1. Schematic representations of Indus inscriptions found on different type of media.

a) Inscribed stamp seal of Mohenjo-daro; b) Inscribed sealing of Harappa; c) Obverse and reverse sides of three inscribed miniature-tablets of Harappa; d) Inscribed copper-tablet of Mohenjo-daro; e) Inscribed ivory-stick of Mohenjo-daro f) Inscribed pottery-shards and vessels.

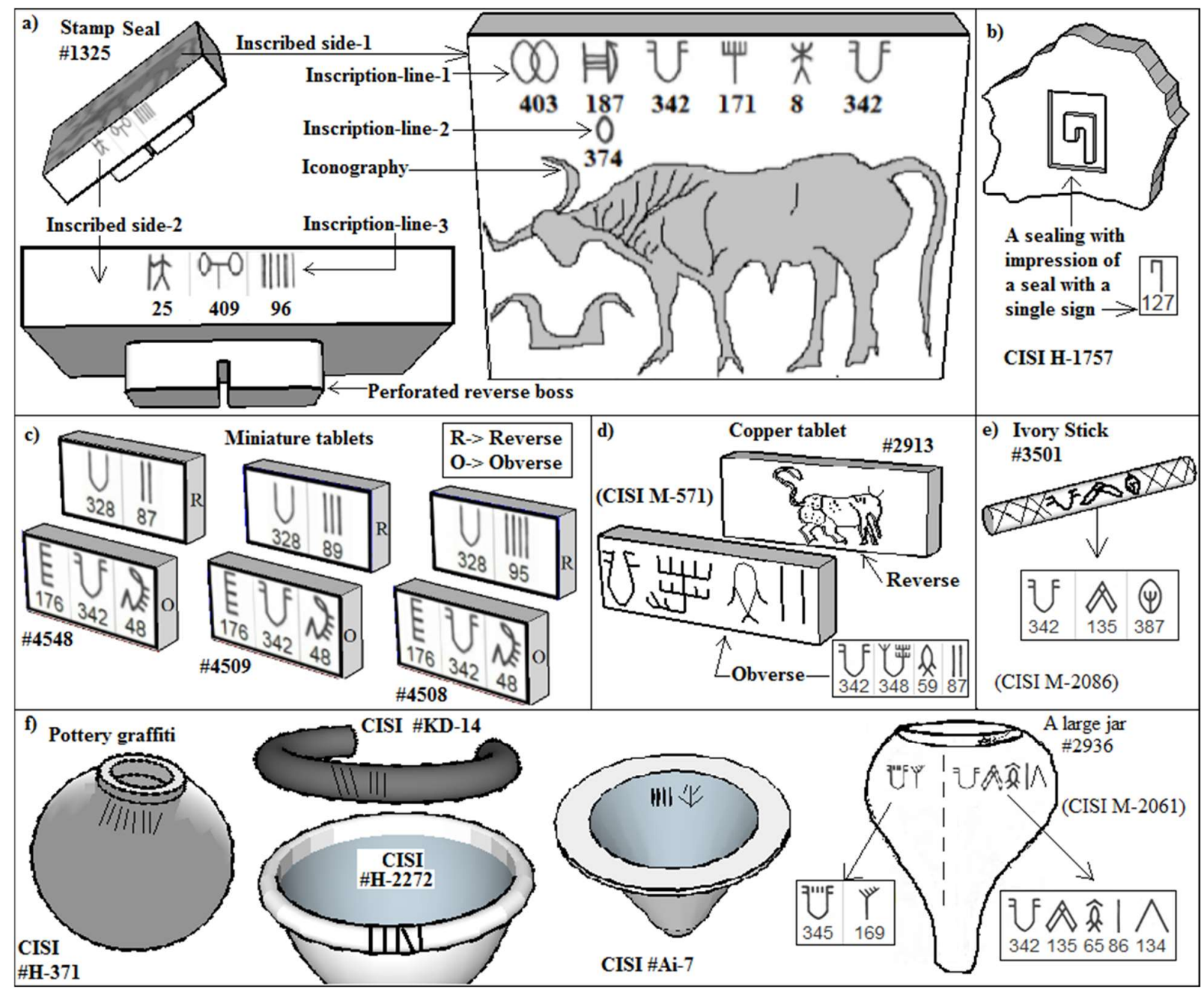


This study proposes to approach the riddle of Indus inscriptions in the way a Sudoku player should approach a sparsely filled Sudoku puzzle, treading cautiously within the boundaries of the available evidence, and proceeding methodically from the known to the unknown.

Figure 2. Indus sign-classes and their member signs.
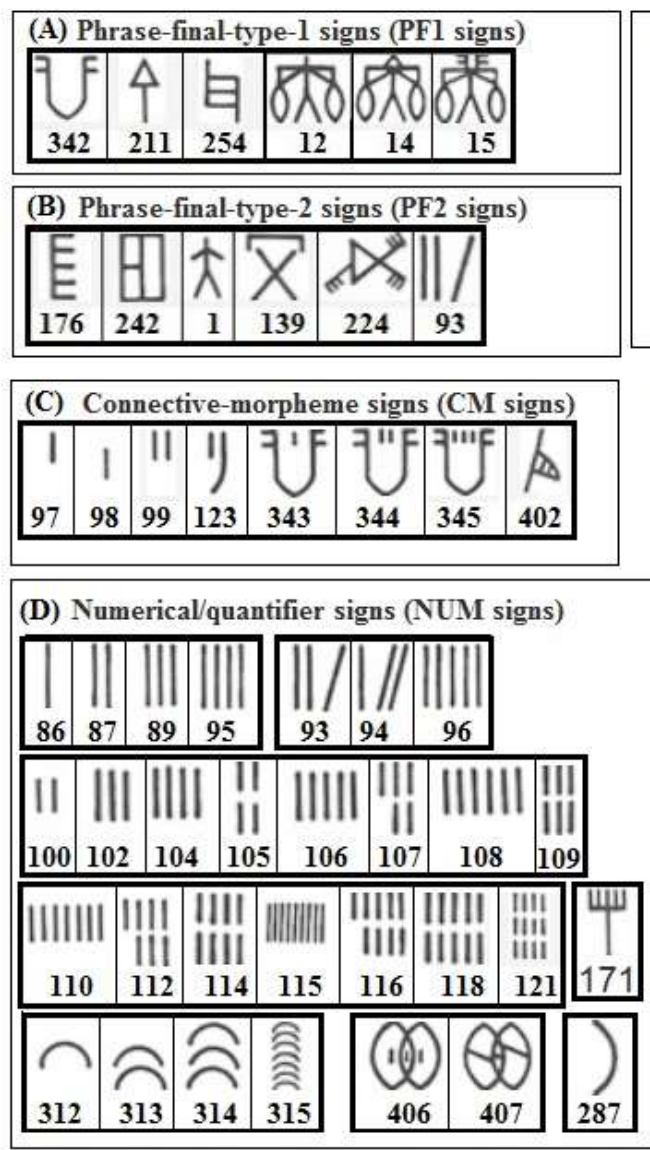
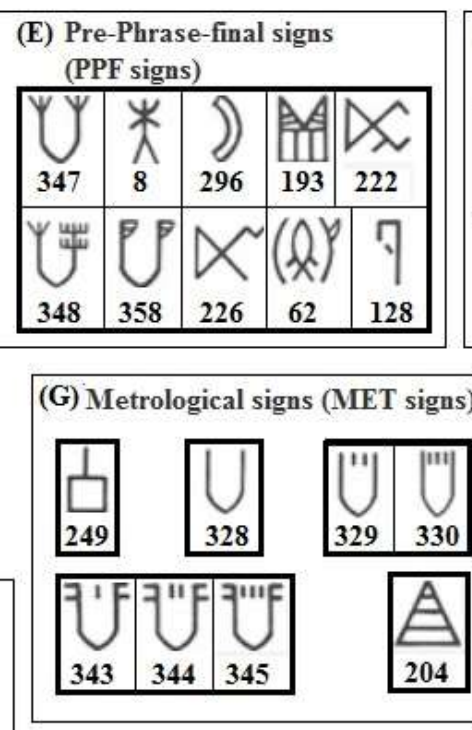

(I) Encapsulated signs (ENC signs)
(F) Pre-Connective lexeme signs (PCL signs)

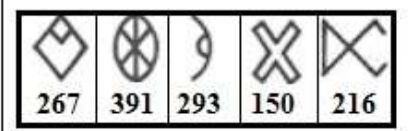

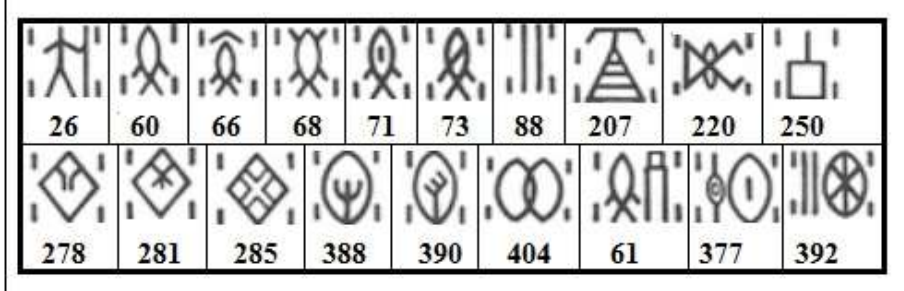

It starts with asking two basic questions: A) 'How did these inscriptions convey meanings?'; and B) 'What kind of meanings were conveyed?'. Both of these questions were partially answered in my previous analysis (Mukhopadhyay, 2019) on Indus script (henceforth Article_19), which has argued through a thorough contextualization of the inscriptions that the inscribed seals/tablets of IVC were "formalized data carriers", whose inscriptions used both linguistic syntaxes, and non-linguistic document-specific syntaxes to convey messages related to certain commercial and administrative activities where metrology and standardization played an important role. (The term "formalized data carriers" was previously used by Nissen et al. (1993: 30), to describe the administrative bookkeeping tablets used in ancient Mesopotamia, where they suggested that the proto-cuneiform Uruk tablets bore "closer resemblance to such modern documents as punched cards, dockets, clearing checks, balance sheets or many other formalized 
data carriers than to independently and freely composed manuscripts in the modern sense"). Most importantly, Article_19 establishes that the majority of the inscriptions were written logographically, maintaining certain pre-defined rules of phrase-structures. Analysing various combinatorial and graphemic characteristics of Indus signs, Article_19 classifies several signs into nine functional sign-classes (see Fig. 2); discusses the features used for their classification; explains the roles such sign-classes played in the syntactic structure of the inscriptions; and finally argues that these sign-classes had not only syntactic roles but also specific semantic roles as they showed many intriguing patterns of co-occurrence restrictions and co-occurrence preferences, which could be driven only by specific semantic restrictions and preferences. The current article builds on the findings of Article_19, and tries to answer certain crucial questions that arise from the structural analysis. Collating several archaeological, historical and linguistic evidence it reasons that the inscribed seals and tablets were administrative tools such as ancient tax-tokens and trade-licences, which were needed to control the enormous and complex trade networks spread through the vast expanse of IVC. It argues that the inscriptions revolved around information such as which commodities were permitted to be produced, manufactured, traded or transported, and what kind of taxes/tithes were paid by the bearers of the inscribed sealings or tablets to be allowed to continue such commercial activities. Many inscriptions also contained additional information about the rate and mode of tax payments and the type of the tax-receiving entities. This study further explores the semantics of a few frequently used Indus signs, and tries to map which sign-classes conveyed which part(s) of the above mentioned information. Even though such claims may initially sound a bit radical and speculative, the subsequent sections would demonstrate that, all these hypotheses are reached logically, tiptoeing within the boundaries of the available evidence. Since the current study reasons that Indus inscriptions had encoded a sublanguage which contained trade-related and metrological terminologies, it opens up a way of tracing out some of the ancient trade-related words and metrological nouns prevalent in IVC and their related Indus logograms, as such words generally show tremendous inertia to change, sometimes surviving for thousands of years (Kula, 2014), spreading quickly across distant countries, and often being borrowed or calqued in otherwise unrelated languages. Since the IVC people had a vibrant trade relationship with the Persian gulf, and some direct and indirect trade relationships with ancient Mesopotamia (Gelb, 1970), this study analyses the trade related ancient documents of Mesopotamia, Old-Persian historical texts, various ancient texts and scriptures of the Indian subcontinent, and ancient texts of certain BMAC-area languages (Old Persian, Khotanese, Sogdian etc.) to trace out certain trade-related words with similar etymological roots that remained fossilized in these languages which were otherwise quite different from each other. This methodology leads to some intriguing results, one of which is finding out the ancient lexical roots used to denote the widely travelled and highly coveted gem stone lapis lazuli. Lapis lazuli has a characteristic blue colour with a typical iridescence that often got compared to the iridescent colour of a pigeon's neck in ancient times, which made the stone 
being referred to as the "pigeon-coloured" stone (see Section-5.6). I demonstrate how we can geographically trace out an ancient "lapis lazuli trade route", and how in most of the regions touched by this route, the colour blue was denoted by different versions of a root-lexeme ("Kapautaka") that means pigeon in many ancient Indic languages including Sanskrit. Based on various related evidence, I also argue that the bird-like logograms used in Indus inscriptions possibly denoted "'lapis lazuli", and other such precious stones. Using similar methods, I trace out the ancient word "mani" that was the word used to signify "bead" of precious stones since IVC, and claim that the fish-like logograms were used to signify "eye-beads", or "fish-eye-beads" which were one of the most precious commodities manufactured and exported by the people of IVC. I also interpret the meanings of signs $\vartheta, \otimes, Y$, etc. using similar methods discussed above. Finally, I seek to decipher a small set of Indus inscriptions, to show that their inscriptions signified phrases close to "Harvest-tax or grain-tax of specified fixed rate, was paid to the treasury", and "Harvest-tax or grain-tax of specified fixed rate, was paid to some sovereign authority or royalty".

\section{Materials and methods}

\subsection{Materials}

The digitized corpus of Indus inscriptions compiled by Iravatham Mahadevan (1977), further enhanced in 1980 (henceforth IDF-80), is the main material used in the structural analysis (for a detailed description of the corpus, and snippets of computer programs used to analyse the corpus, see Article_19). The study also uses the excellent photographic corpora (henceforth CISI) created by Dr. Asko Parpola and his colleagues, (Joshi \& Parpola A, 1987; Shah \& Parpola A, 1991; Parpola A, Pande \& Koskikallio, 2010) to visualize the inscribed objects; and the intricately compiled corpus created by Bryan Wells and maintained by Andreas Fuls, (henceforth ICIT, available at http://caddy.igg.tu-berlin.de/indus/welcome.htm, last accessed on May 2016), to reverify certain doubtfully read inscriptions of IDF-80, and to accommodate a few inscriptions that are not present in IDF-80. The other materials used for the analysis are ancient texts, historical and archaeological books and documents, and books and articles written on ancient languages and general linguistics. The methodology discussed below would justify the apparently anachronistic use of certain ancient texts in the semantic analysis.

\subsection{Methods}

The results of the structural analysis performed in Article_19 form the main empirical basis of this semantic analysis. Since according to it, the majority of the Indus inscriptions (if not all) were logographically written, and contained demonstrable semantic compositionality, to 
understand the semantics of any inscription (e.g. $\Psi \quad$ III $\quad$ I $\$$ ), we must analyse the meaning conveyed by each of its constituent signs (e.g. $\otimes, \omega, \mathrm{III}$, and $\Psi$ ). (Here it is important to mention that all the inscriptions in this study are presented as normalized in right-to-left direction, true to the dominant direction of "writing" in Indus script). But guessing the morphemic/lexical meaning of a logogram, without knowing the underlying language used in it, is an arduous undertaking. In this error-prone task, the script-internal evidence of the usagepatterns of a sign, the archaeological contexts and types of artefacts the sign frequently occurs in, the features of the functional class the sign belongs to, and the graphemic characteristics of the sign, would serve as indispensable clues.

Now, while the script-internal and archaeological evidence are empirical in nature, the method of interpreting the graphemic characteristic of the signs is not so straightforward and demands consideration of many other factors. In the initial stages of evolution of a logographic script, its logograms generally carry discernible graphical similarities with certain objects that are associated with the meaning conveyed by the logograms. For example, in Mycenaean linear-B script, the "glyph for flour was a figure holding a pestle" as the crop Emmer, used to make flour, was "deglumed in a mortar throughout the Mediterranean and Near East" (Harlan, 1998:99). In Egyptian Hieroglyphic too, mortar-pestle was used as determinatives for the verbs "pound" and "press down", and also as determinative for certain adjectives that means "heavy" (Gardiner, 1969:520). As Chadwick explains (1990:46), because of certain obvious ideograms used in Linear$B$ inscriptions (cup, tripod, horse etc.), "in many cases it was possible to deduce the general subject-matter of the tablets before a single syllable could be read". In Chinese character system, the use of many logographic symbols, which signify concepts rather than their pronunciations, enabled illiterate Chinese people, speaking different varieties of Han languages, to understand the logographic elements of a written Chinese text, although they might not understand each other as they speak (Rowe and Levine, 2015:288). Similar approaches can be taken for interpreting Indus logograms.

However, with time, some logographic scripts evolve their logograms to assume more abstract and simple forms, which may not anymore resemble the original objects/concepts associated with their meanings. For example, the bull ("GUD") pictogram of Sumerian cuneiform, evolved from or $\bigcirc$ ca.3200 BC Uruk, through Assyrian (Woods, 2011). Here the last form is no more usable for connecting the logogram to the meaning of "bull" based on visual interpretation. Therefore, before making visual interpretations of Indus signs, it is important to find out whether those signs found in the seals/tablets were in a stage that retained sufficiently pictographic features. Fortunately, a lot of 
Indus logograms had clearly retained their pictographic nature. For example, the versions

and of sign 8 , present in seals \#5123 (CISI \#H-1046) and \#9842, show beyond doubt that the basic grapheme present in the phrase-final signs $8 \times, 8$, 8 , and "bearer carrying some loads in shoulder pole". Mahadevan (1977) has recorded many such different graphemic versions of related signs, which undoubtedly resembled certain objects/animates familiar to the people of IVC.

But, even had Indus logograms retained their pictographic features, not all logograms of an ancient writing could be interpreted by directly associating a sign's grapheme with its interpretation made by our modern eyes. The ancient culture prevalent in the region and the spoken language(s) used in the region can play a crucial role in expressing ideas through metonymy, homonymy, polysemy and more such sophisticated mechanisms. For example, as mentioned in Article_19, "the pictographic symbol of bevelled-rim bowls had entered the protoSumerian texts as an ideographic sign 'ninda' (initially $\underline{D}$, then transformed to [D. Since bevelled-rim bowls were vessels of standardized quantities, possibly used in daily ration disbursement, the 'ninda' symbol, which was a standard measurement unit, also metonymically signified grain-ration (Nissen et. al, 1993:70-71)". Now, without a thorough knowledge of Mesopotamian history, the semantics and etymology of $1 D$ would possibly have remained inscrutable to Sumerologists. Comparably, ability to guess the symbolisms associated with Indus logograms requires some understanding of the socio-economic norms prevalent in IVC.

Unfortunately, unlike the situation in ancient Mesopotamia or Egypt, where various types of written documents contemporary to their scripts (ranging from scribal lexicons, administrative documents to mythological poems), abounded, no such written documents (except Indus inscriptions) of Indus era (ca. 2600-1900 BCE) are yet found from the Indo-Pakistani subcontinent, creating yet another obstacle to deciphering the script. But, this study could partially overcome this issue by narrowing down the semantic scope of the inscriptions, and depending on the known inertia of metrological and trade-related terminologies, and their borrowing, calquing, and adaptation by the languages of distant civilizations connected through trade and allied standardization processes. Since this study uses the early Vedic texts, Jātaka scriptures, and Kauțilya's Arthaśāştra, to probe the long-standing metrological and trade-related words used in the ancient Indo-Pakistani subcontinent, I need to establish whether certain parts of the material culture of IVC continued in this region, and thus might be documented in these ancient texts, even if they were compiled centuries after the Indus era. 
After the Integration Phase of IVC (2600-1900 BCE), the use of standardized weights and inscribed objects declined abruptly in Indus regions. Meluhha and other Indus locations no more found reference as source or entrepôt of traded materials in ancient Mesopotamian documents in the later part of 2nd millennium BCE (Gelb, 1970; Moorey, 1999), as the long-distance trade of Indus people with Mesopotamia and Persian Gulf also stopped at the same time. Still, in the Late Harappan age (1900-1300 BCE), "the region around Harappa was not abandoned, but there was a continuity of occupation in the Punjab up through the Early Historic Mauryan period" (Kenoyer, 2006:13). Most importantly, the metrological system of Indus people, which was standardized across various Indus settlements spanning almost one million square-kilometres, continued (as expected from the inertia of traditional measurement standards). Archaeologists and numismatists have discovered that the weight standard of IVC had a strong influence on the numismatic standards in historical India. As described in Arthaśāstra (composed in Mauryan era, around $400 \mathrm{BC}$.), the seeds of abrus precatorious, also known as raktikā, kṛsnnala or guñjā seeds, were used as the basis of the weight system prevalent in ancient India. According to Kosambi (1975:174), 95\% of the 1059 punch-marked coins found in Taxila hoard, minted under Magadhan influence, "fall into the same range of variation in weight as do the accurately cut and very wellpreserved ' $D$ ' class stone weights found in the Indus city excavations. The standard accords very well with the 32-raktika weight of the traditional karsapana". Intriguingly, in Taittiria Samhitā, Kāțhaka Samphitā and other Vedic texts which are composed in c. 1200 B.C. to 1000 B.C., kṛṣnala seeds are mentioned as units of gold measurement (Kosambi, 1975:121; Macdonell and Keith, 1912a:185; Bhandarkar, 1921:60). Thus, the continuity of the metrological systems of Mauryan period could be traced back to the Vedic period and even to the IVC era. The fact that even after the official adoption of metric system in 1956 in India, "ratti" (the measure based on raktikā seeds) is used to weigh gold and other gem stones in many urban and rural locations till date, proves how certain metrological standards defied change for almost four millennia. Many other metrological units (e.g. aratni, khārī, kṛṣnala etc.) mentioned in the Buddhist scriptures (c. 600300 BCE) and Arthaśāstra (c. 400 BCE) (Shamasastry, 1929), were also mentioned in Rigveda (Macdonell and Keith, 1912a), whereas the same units were current in India even in the eleventh century, as known from their use in the famous mathematical treatise Līlāvatī of Bhāskarācārya, composed in eleventh century AD (Taylor, 1816). Moreover, the administrative methods described in Arthaśāstra, such as the need of fortifying a city, importance of controlling the production and trade of various merchandise by the state, and the necessity of using standardized metrological systems and seals across the state's locations (Rangarajan, 1992), matches nicely with the archaeological evidence regarding the use of seals, weights and fortified city areas in IVC (Kenoyer, 2010:109). In fact, Kautilya, the author of Arthaśāstra, was a scholar from the great ancient city Takșaśīā situated near river Indus, which had been a city since at least 1000 BCE, and was inhabited even before the early Harappan era (Allchin and Allchin, 1982:127,314). Thus the material culture in Mauryan Takṣaśilā must have had some continuity 
with its ancient urban material culture, dating back to IVC. Moreover, although written in $400 \mathrm{BC}$, Kautilya himself stated that his Arthaśāstra was a compendium of many earlier Arthaśāstra writings (Drekmeier, 1962:193). Hence, Arthaśāstra evidently recorded the accumulated knowledge of a much more ancient material culture prevalent in the north-western IndoPakistani subcontinent. Similarly, the Rigveda, composed around 1200 BC (Flood, 1996:27-39), was "by and large composed in an area that overlaps with that of the Indus civilization, the Greater Panjab" (Witzel, 2000). Thus, Rigveda should be treated as "a lively testimony of the poetry, religion, society and the language(s) of the northern half of the Indus area during the immediate post-Harappan period, the localization period of the second millennium BCE" (Witzel, 2000). So, while avoiding the much-debated topic about whether the Vedic people were same as the people of IVC, and whether their religious practices overlapped, I can at least claim that the metrological terminologies mentioned in Rigveda must have been influenced by the wellestablished metrological system of IVC to a good extent. Similarly, even if composed between 600-400 BC, the Jātaka stories are "almost throughout loans from the ancient "pre-Buddhist national tradition of India" (Bühler, 1898:18). Hence the material culture of ancient India, as extracted from various Vedic, Buddhist, and other ancient religious scriptures, and the treatise like Arthaśāstra, can be used in understanding certain socio-economic aspects of IVC, and can immensely help in understanding the cultural symbolisms used in Indus graphemes, despite the fact that these texts were composed several centuries after the peak Indus era.

Additionally, since IVC had a vibrant trade relationship with ancient Persian Gulf and to some extent with ancient Mesopotamia, certain parts of Indus material culture possibly remained fossilized in the Mesopotamian and Old Persian documents. For example, in the documents of the Assyrian king Tiglath-Pileser IV (745-727 BC), the word "šin pīri" means ivory (Rogers, 1912). As documented in Assyrian dictionaries, šin is derived from the word "šinnu", which meant "tooth", "elephant tusk", "ivory" etc. (Reiner, 1992), whereas the words "pirru", "pēru", "pīlu", "pēlu" etc. meant elephant in Old Babylonian (Roth, 2005). In Old-Persian language, "piru" meant ivory (Tavernier, 2007). In Prakrit, and Sanskrit, "pīlu" means 'elephant', whereas in Dravidian languages "pallu", "pella" and "pel" signify elephant and elephant-tusk (Narain, 1991; Kittel 1894). Interestingly, after analysing the reports of Jarrige, Ratnagar and other archaeologists, Moorey (1999) states that, archaeologically the earliest evidence of ivorycraft in the world was a grooved elephant tusk found at Mehrgarh (5500 BC), a long-standing IVC location. The ivory seal and gaming piece of c. $3000 \mathrm{BCE}$, the next oldest ivory artifact in the world found at Mundigak, was an urban settlement having cultural interactions with IVC (Moorey, 1999:116). Moreover the ivory objects imported into Mesopotamia from Dilmun and occasionally Meluhha, often had Harappan parallels. Hence the "piru"-based words for ivory must have originated in IVC (as the ancient Egyptian words used for African ivory are "ab", "abu", "āb", behu, "netcheh-t" etc. (Budge, 1920), with no phonetic connection to "piru"), and their permeation in 
the languages of distant countries must be attributed to the ancient ivory-trade, the Asian part of which was dominated by the IVC traders. Thus, studying various types of literary evidence, and analysing the common substrate words used for various traded commodities that had similar roots in a wide range of otherwise different languages, this article seeks to find the names of certain widely-travelled traded commodities that should have originated in IVC, and then tries to trace those nouns to certain Indus logograms, as the trade and tax-related records conveyed through Indus inscriptions must have contained names of certain ancient commodities.

In sum, methodologically this article sifts various archaeological, linguistic, historical and script-internal evidences, to connect certain dots that possibly remained quite unnoticed in the existing Indus script research.

\section{Results and discussion}

In the initial part of this section, the structural aspects of Indus inscriptions, as explored in Article_19, are briefly discussed, followed by a list of questions arising from the analysis which should both guide the semantic investigation, and get explained through it. Since the semantic analysis does not take a linear path, interrogating a single sign may touch manifold layers of evidence, many of which are also needed in the analysis of other signs. Thus, to facilitate easy navigation and cross-referencing, all the hypotheses of this study are listed upfront, and then rationalized in subsequent detailed sections.

\subsection{The structural aspects of Indus inscriptions}

\subsubsection{The sign-classes in Indus inscriptions}

Among the Indus inscriptions excavated so far, the majority (if not all) are logographically constructed semantically complete phrases, which maintain quite formulaic phrase-structures. Almost all Indus signs function as morphemes and lexemes, some of which are general information-carrying lexemes appearing in various positions of the inscriptions, whereas others belong to specific functional classes (see Fig. 2) and occur in more specific positions in the inscriptions' phrase-structures.

As shown in Fig. 3A, the Phrase-final-type-1 (PF1) signs almost always occur in the terminal positions of Indus semantic phrases, and barring a few exceptions, the Phrase-final-type2 (PF2) signs generally occur following either the PF1-signs or the CROP-signs in the terminal positions of inscriptions. The Pre-phrase-final (PPF) signs, as their class-name suggests, 
demonstrate a strong affinity towards the PF1-signs, and precede the PF1-signs in almost all of their (PPF-signs') occurrences (Fig. 3A).

Figure 3. Representative examples of typical usage patterns of Indus sign-classes:

(a) Phrase-final and Pre-phrase-final signs; (b) Connective-morphemes and Pre-connective lexeme signs; (c) Metrological and Numerical signs; (d) CROP signs; and (e) Encapsulated signs.

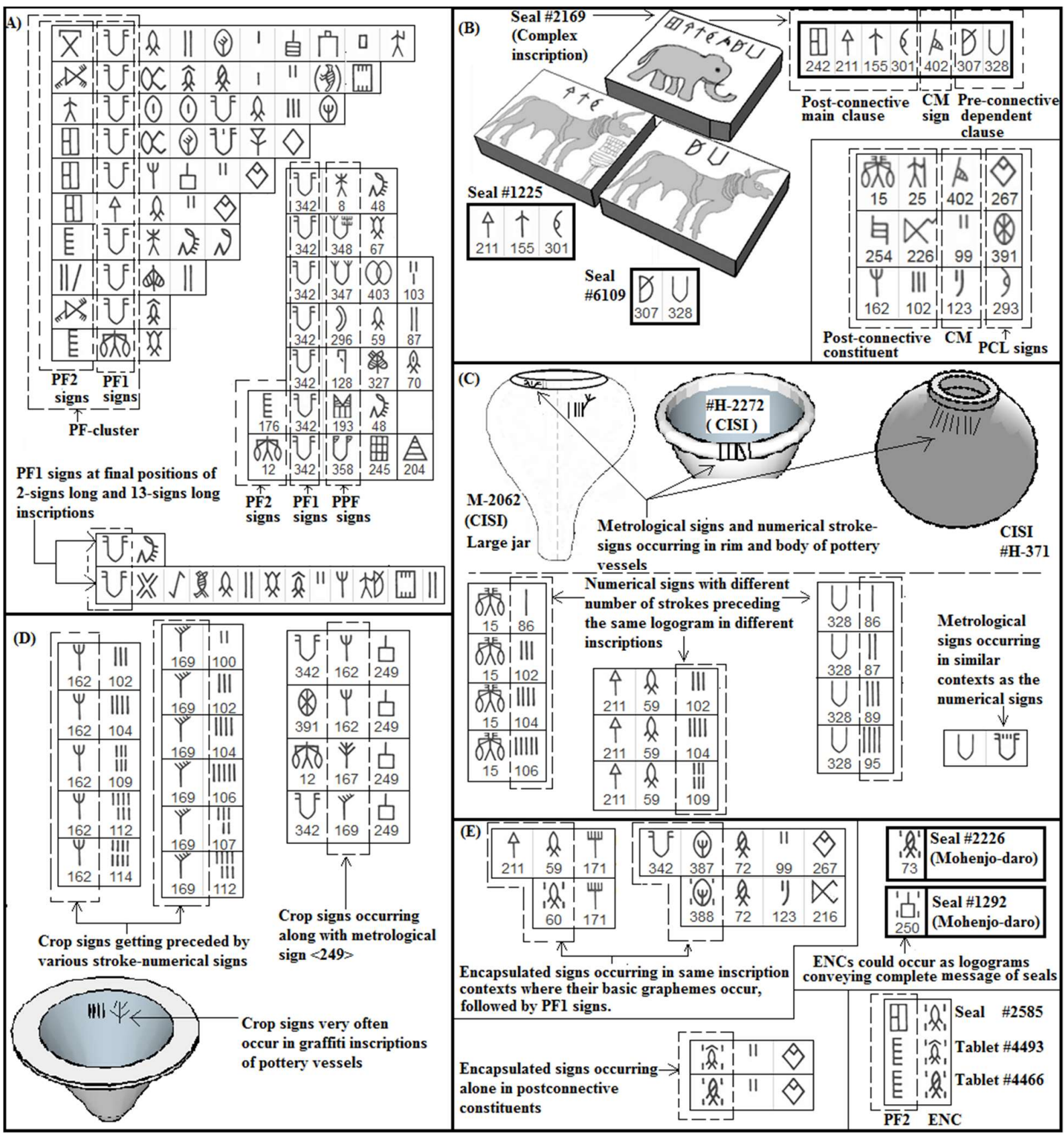


Indus inscriptions also use certain numerical (NUM) signs, many of which are graphically strokesigns (Fig. 2D). These signs generally precede certain specific lexeme signs. The pattern where often the same lexeme sign gets preceded by different number of strokes in different inscriptions (Fig. 3C-D), strongly indicate that those lexeme signs were getting quantified by the NUM-signs in some predefined way. Another class of quantifier signs are the Metrological (MET) signs (Fig. $2 \mathrm{G})$. These signs generally occur in similar inscriptional contexts as the NUM-signs in inscribed seals, sealings, tablets and pottery vessels (Fig. 3C). Certain groups of MET-signs (e.g. U, U,

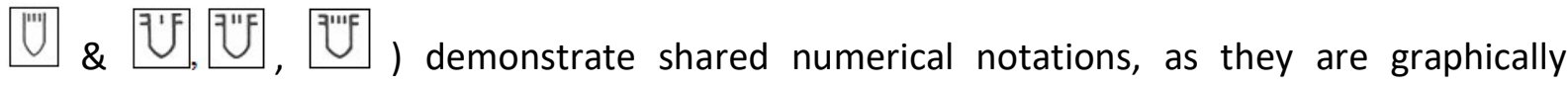
constituted by putting different number of strokes inside their basic graphemes. Unlike the NUMsigns whose numerical values possibly vary depending on the context and the objects of quantification, the values of the MET-signs arguably remain constant and represent different denominations of certain metrological standards (conveyed through their basic graphemes $U$, U etc.) prevalent in ancient IVC (Article-2019). The CROP-like (CROP) signs are graphically phytomorphic signs (Fig. 2D). They frequently occur in the terminal positions of Indus inscriptions (Fig. 3D), and demonstrate a strong affinity towards the NUM and MET signs. Interestingly the MET-signs and the PF1-signs demonstrate a peculiar connection both in graphemic and

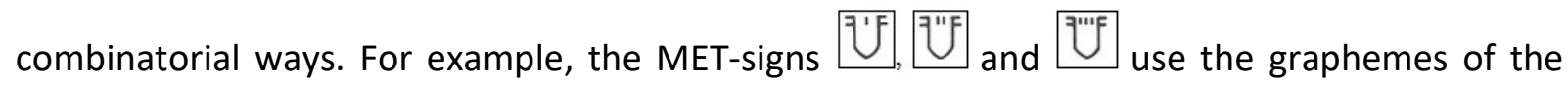
most frequent PF1-sign U. Now, in logographic scripts, the choice of similar graphemes for different logograms strongly indicates some underlying semantic connection between them. Moreover the MET-sign $\square$, which shows a strong association with CROP-signs (Of 299 DILs where CROP-signs occur, 112 DILs contain <NUM-CROP> constructs, whereas in 73 DILs precedes the CROP-signs), reveal an arresting combinatorial pattern. When preceded by NUMsigns, CROP-signs mostly occur in the terminal-positions, without any PF1-signs following them. But, when CROP-signs are preceded by MET-sign $\square$, in 87\% cases some PF1-sign follows the

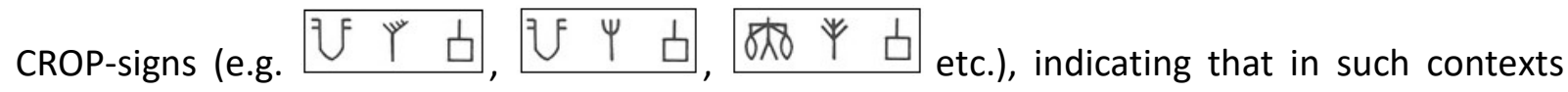
MET-sign $\square$ semantically replaces the NUM-signs, and in doing so it needs PF1-signs to follow the constructs. This indicates an indirect semantic link between PF1-signs and metrology.

The Indus signs classified as Encapsulated (ENC) signs stand out for their typical graphemic feature of having certain basic graphemes enclosed inside 4-stroke circum-graphs (Fig. 2I). As argued in Article_19, the ENC-signs are composite lexemes that assume both the semantic value of their basic graphemes and the functionality of PF1-signs (see Fig. 3E). 
As shown in Fig. 3B, certain Indus inscriptions can be considered as grammatically complex phrases, made of a dependent clause and a main clause, which get connected through a specific class of signs categorized as Connective-morphemes (CMs) (see Fig. 2C). As deducted in Article_19, the CM-signs are functional morphemes that play some kind of subordinating connective roles in complex Indus phrases, whereas some of them also occur as coordinating conjunctions in some composite inscriptions. The semantic scopes of the pre-connective dependent clauses and the post-connective main clauses are visibly different based on their distinctive sign usages. Often the pre-connective phrases are constituted of only single signs. There are 92 distinct lexeme-signs that have occurred alone as pre-connectives in the inscriptions

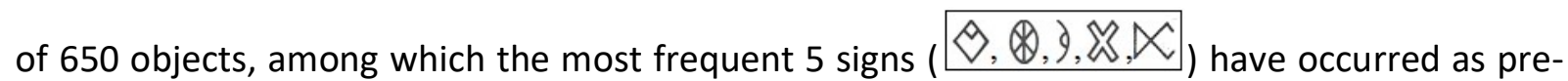
connectives in 500 objects. The fact that only " $5 \%$ of the 92 signs occurred as pre-connectives in more than $75 \%$ of such objects irrefutably proves that certain signs were much more suitable to the semantic scope of pre-connective constituents than others" (Article_19). These 5 signs are classified as frequently pre-connective-lexemes or PCLs (see Figs $2 f$ and $3 b$ ). As argued in Article_19, both the pre-connective and post-connective constituents of any completely legible and undamaged complex inscription are semantically complete phrases. The pattern that the pre-connective constituents occur alone in the inscriptions much less frequently compared to the post-connective constituents, is arguably driven by the semantic role played by the preconnectives in the domain of Indus inscriptions.

To visualize the formulaic patterns maintained in most of the Indus inscriptions, we can gloss the inscriptions by replacing each classified Indus sign with the name of the functional-class it belongs to (if any), and each unclassified lexeme sign by the word LEX. The examples in Fig. 4 shows how different Indus inscriptions often belong to the same glossed-groups and share the same morpho-syntactic patterns.

\subsubsection{Co-occurrence preferences and co-occurrence restrictions}

As discussed in Article_19, there are many "true collocations" used in Indus inscriptions, which can get further distinguished "between 'general collocations', where certain signs frequently co-occur due to the semantic relationships shared by their sign-classes, and 'fixed collocations', where the co-occurrences are driven by the semantic bonds between the individual signs". For example, the co-occurrence preferences between the NUM-signs and CROP-signs (see Fig. 3d examples) should be considered as 'general collocations', as they are based on the semantic relationship between two functional sign-classes. Thus the $<N U M C R O P>$ constructs like

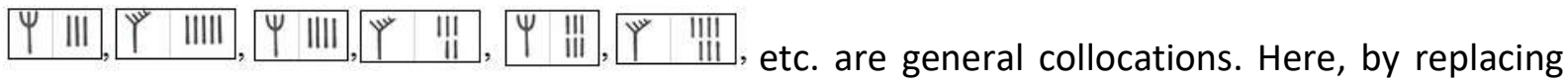
CROP-sign $\Psi$ of $\Psi$ III with another CROP-sign $Y$, one can rightly surmise the existence of 
Y III. Contrarily, III (b) (101 DILs), is a "fixed collocation", as here sign occurs exclusively with a specific NUM-sign $1 \|$.

Figure 4. Certain Indus inscriptions grouped by their glossed patterns.

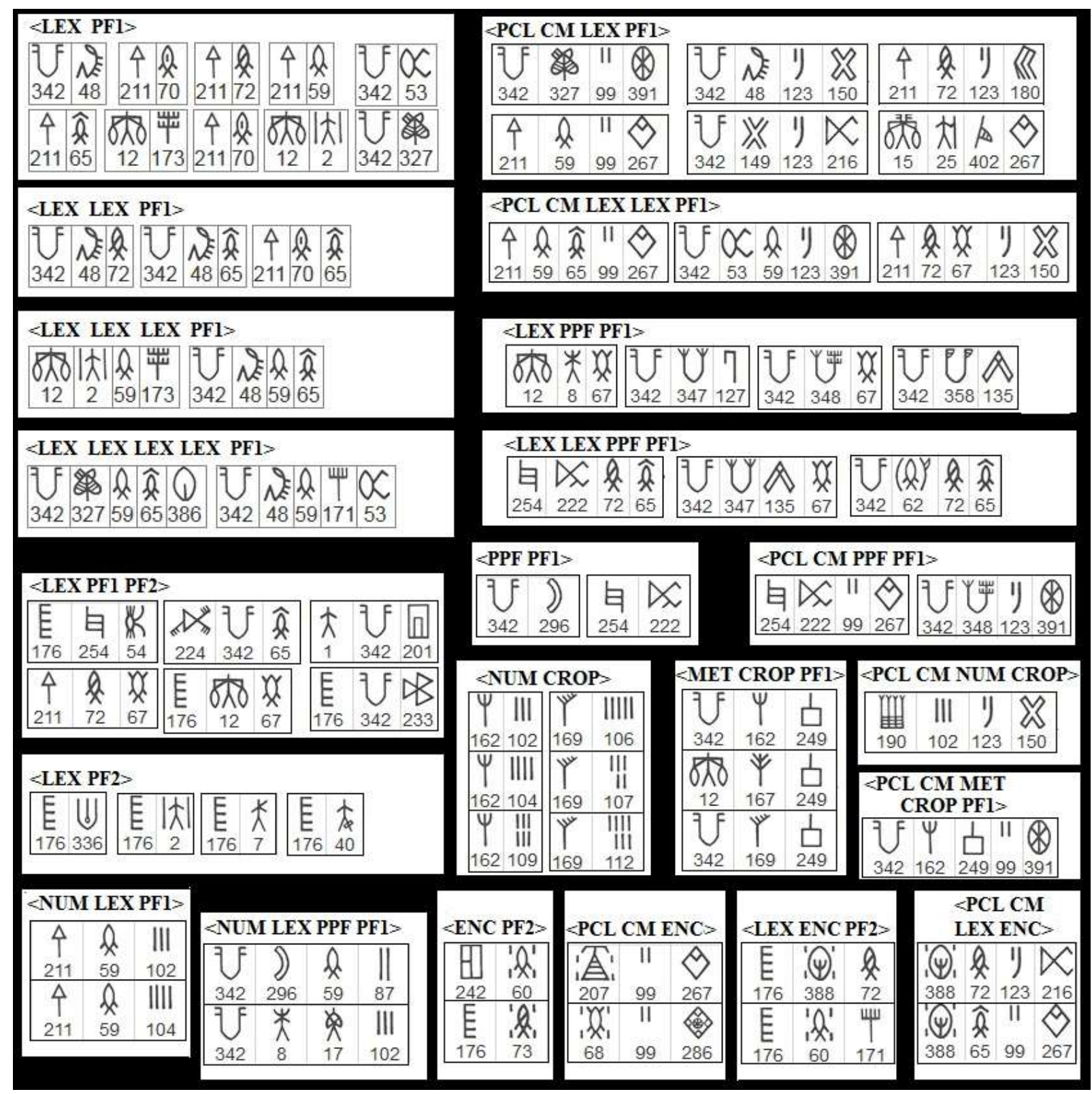

Thus, replacing the $\|\mid\|$ of $\||| \mid$ by any other stroke-numeral does not generate any collocation that actually occurs. Indus collocations are mostly limited to bigram-collocations and a very limited set of trigram-collocations ( $\mathbb{X}, \alpha M \frac{W}{0}$ ). Article_19 has shown how these 
collocations demonstrate semantic compositionality, where unlike idioms, the meanings conveyed by them are directly formed by the meanings of their constituent signs. In certain cases, the collocates can be easily distinguished as attributive-lexemes, and substantive-lexemes (e.g.

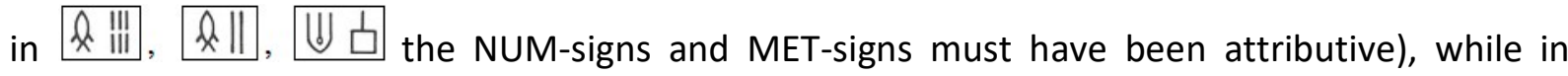
certain cases two substantive-lexemes co-occur (e.g. $1 \mathrm{~m}$ ), possibly forming genitive-like constructs where one nominal sign qualifies the other.

Indus inscriptions also contain many instances of duplicated signs ( 压, 曲 曲, 这邻) and a few triplicated and quadruplicated sequences

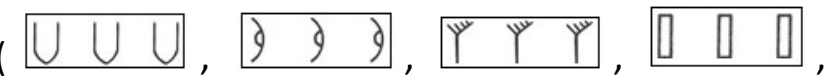
$\left.\begin{array}{llll}\Psi & \psi & \psi & \Psi\end{array}\right)$. Article_19 argues that some of the sign-repetitions were possibly some morphological tool used to introduce certain semantic changes. For example, while sign seldom occurs in phrase-final positions, it duplicated counterpart 曲曲 frequently assumes the

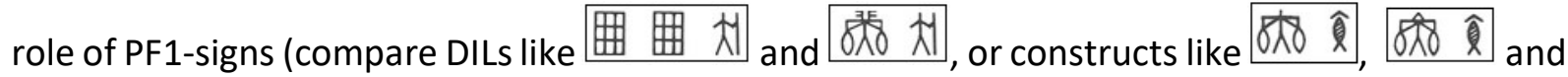
曲曲 弇). Moreover certain signs, particularly those which often get preceded by numerals, share, when repeated, intriguingly similar inscriptional contexts with their corresponding <NUM

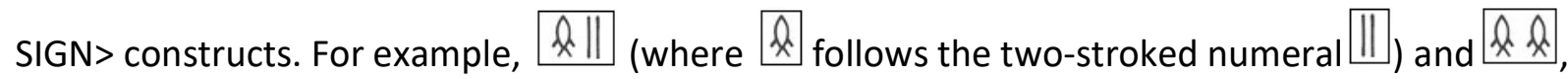
share very similar inscriptional contexts, indicating that in such constructs, duplication possibly has served a similar quantifying role as the NUM-sign $[\|]$ (see Article_19).

The co-occurrence restriction patterns demonstrated by certain Indus signs are even more interesting than the co-occurrence preference patterns discussed above.

For example, in IDF-80:

- Not a single inscription-line contains more than one PPF-sign.

- The PF1-signs rarely occur adjacent to each other. Only 9 DILs contain <PF1 PF1>

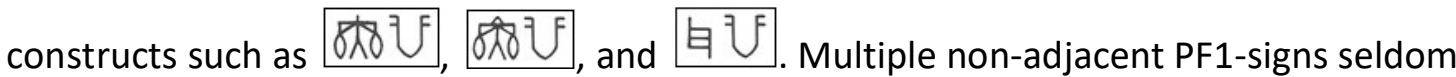
occur inside the same semantic unit.

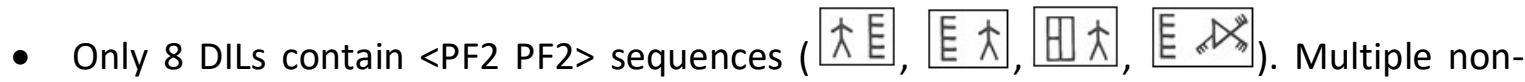
adjacent PF2-signs rarely occur in an inscription-line.

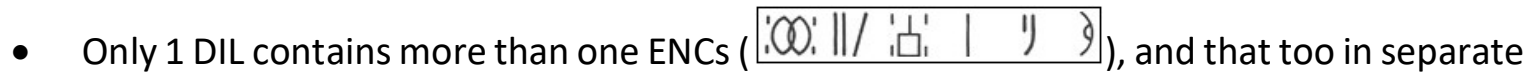
semantic units. 
- Not a single inscription exists where a PPF-sign has preceded an ENC-sign. But, as ENCsigns also contain the semantics of PF1-signs (see Fig. 3e), the way PF2-signs follow ENCs (Fig. 3e), PPF-signs should have expectedly preceded them in some inscriptions.

Article_19 analyses these co-occurrence restriction patterns to establish the logographic nature of Indus inscriptions, and argues that phonological co-occurrence restrictions are based on certain "physical and physiological properties of the speech production and perception systems," such as "'articulatory economy', 'auditory contrast' and 'articulatory-acoustic stability'" (Solé, 1999). Therefore, phonological co-occurrence restrictions are completely different in nature from their semantic counterparts. This is why phonological co-occurrence restrictions pertain to the locales of syllables, morphemes and small words only, seldom operating in larger domains of phrases or sentences. Often phonemes that cannot co-occur in a syllable can appear in the root and suffix of a polysyllabic word (MacEachern, 1999:28). Contrastively, semantic co-occurrence restrictions, originating in needs of logical compatibility between different linguistic elements, operate at the levels of collocations, phrases, sentences and even discourse (Cruse, 1986:103104, 277-279). Since the co-occurrence restriction patterns of Indus signs are maintained in both longer and shorter Indus inscriptions irrespective of the inscription lengths, such inscription-level co-occurrence restrictions must be driven by semantic reasons, as phonological restrictions by nature cannot operate in such larger scopes.

Article_19 also establishes that there is generally no difference between the phrase-structures of long and short composite inscriptions (e.g.
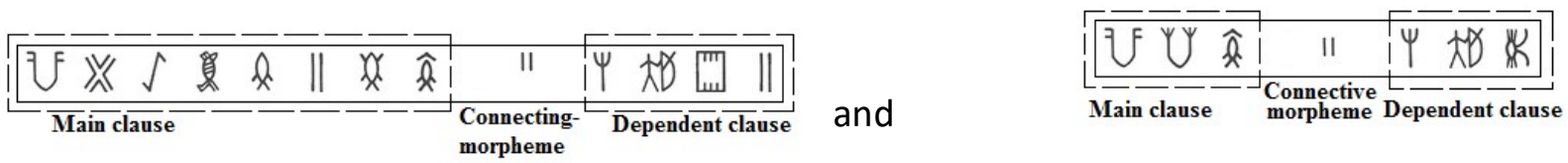

), as they only differ by the count of informational units contained in them. More importantly, my structural study discusses an crucially important aspect of Indus inscriptions, i.e. their semantic compositionality, where the message of a comparatively longer inscription is constituted of the messages found in many other shorter inscriptions found in other inscribed artefacts. The 13-signs long inscription analysed in Fig. 5, is visibly constituted of 5 such informational units that constituted the messages of many shorter inscriptions. 
Figure 5. Demonstrating the semantic compositionality of a 13-signs long composite inscription.

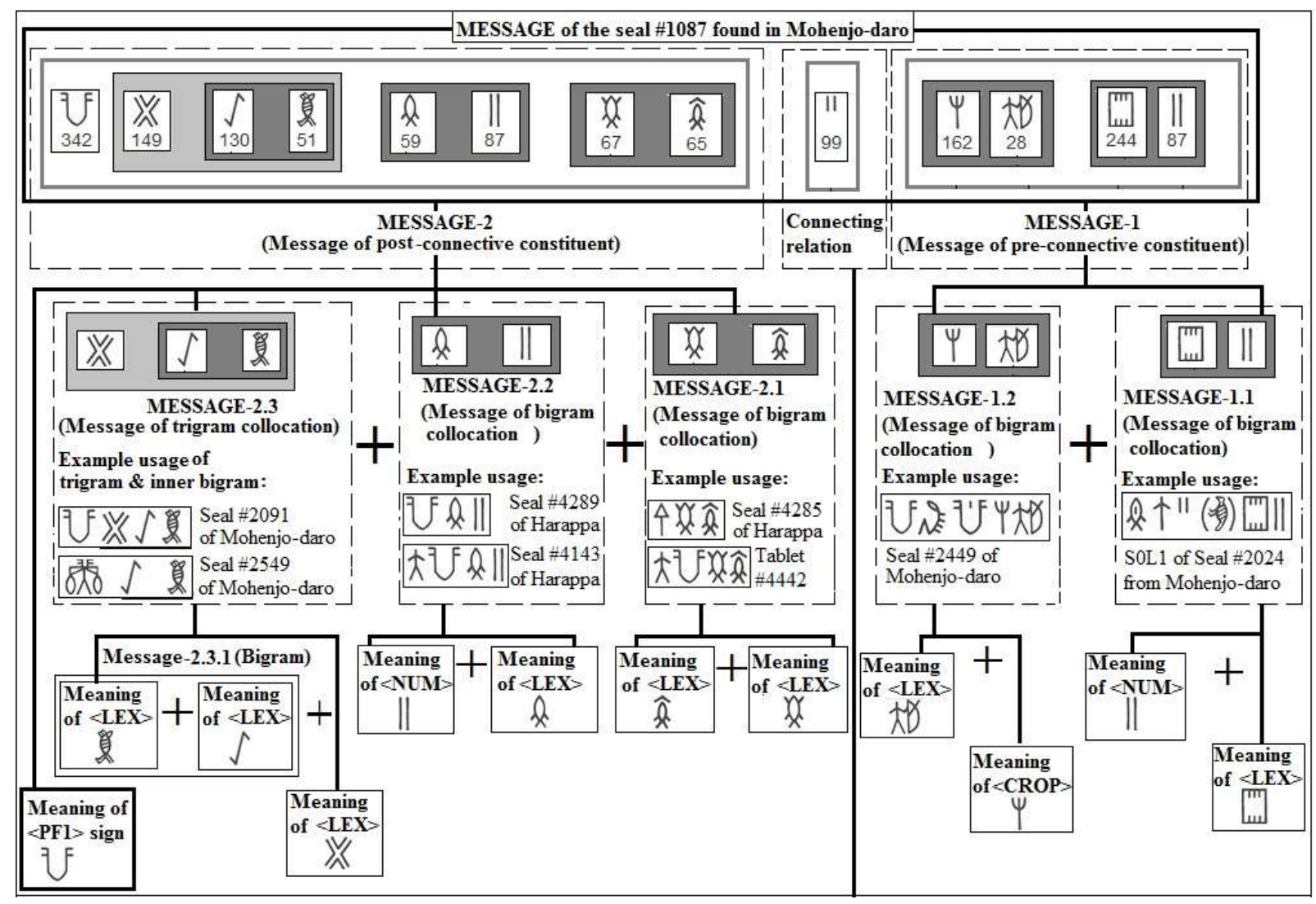

\subsection{Questions arising from the structural analysis}

The following questions, arising from the structural analysis summarized above, should be considered as the guardian angels of the current semantic analysis, as these questions should shape the way of the semantic investigation and also should be explained through the semantic model proposed.

Question-1: What were the semantic roles of the functional sign-classes (PF1, PF2, PPF, CM, PCL, NUM, MET, CROP, and ENC signs) in the semantic scope of Indus inscriptions?

Question-2: Was there a relationship between the semantic role of Indus signs and the graphemes chosen for them? 
Question-3: Why did the numerical and metrological signs occur in such fixed patterns before specific lexemes? Since the usage patterns of these quantifier signs were not suitable for expressing any random number, they could not have represented ad hoc quantities of some commodity exchanged in day-to-day commercial transactions. Then what kind of quantification did they represent?

Question-4: A numerical sign is supposed to be attributive in nature, numerically qualifying its

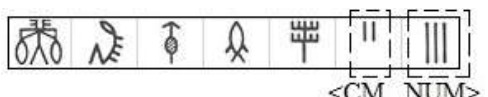

(seal \#4229),

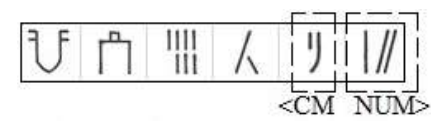

(Seal

\#1113)，

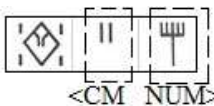

(Seal \#8033), etc.) the NUM-signs occurred alone in the pre-connective constituents, like the substantive lexeme signs? What was their semantic role in such inscriptions?

Question-5: The PF1-signs were related to the MET-signs as they shared similar graphemes and related combinatorial patterns. But the phrase-level role of PF1-signs strongly indicates that they were not directly used as metrological signs, as in that case they had to be repeated before each lexeme-sign they quantified, rather than occurring in the terminal position irrespective of the length of the phrase. Moreover, the PF1-signs occur in a significant majority of Indus inscriptions, indicating their importance in the semantic scope of the inscriptions. What kind of semantic role of PF1s had driven such usage patterns?

Question-6: How did the semantic functions of PF1-signs and CROP-signs overlap, so that the CROP-signs could occur in the terminal position of Indus phrases just like the PF1-signs? Why did the CROP-signs have such a great affinity towards the numerical and metrological signs?

Question-7: How did the semantic scopes of the pre-connective subordinate clauses and the post-connective main clauses differ, as indicated by their different morpho-syntactic characteristics and distinctive sign usages? What was the connection between the preconnective and the post-connective phrases, so that they could be combined to form longer Indus messages?

Question-8: Various zoomorphic Indus signs containing fish-like, bird-like, and other animal-like graphemes were used as lexeme-signs in the inscriptions. What did these signs signify? What was the relation (if any) between the semantics of those signs and their chosen graphemes? 
Question-9: How do we explain the co-occurrence preferences that exist between certain classes of Indus signs and the co-occurrence restrictions existing between the others? For example, why did the PPF-signs have such a great affinity towards the PF1-signs whereas there is not a single inscription-line where a PPF-sign preceded an ENC-sign? Since the ENC-signs contained the semantics of the PF1-signs along with the semantics of their basic graphemes, and the PPF-signs mostly occur before the PF1s, it could be expected that PPF-signs precede the ENC-signs in a few inscriptions. The total absence of this pattern strongly suggests that either the meanings of ENCsigns were not semantically compatible to the PPF-signs, or the ENC-signs also contained the semantic role of PPF-signs, making the PPFs redundant. The semantic explanation of the inscription needs to explain the existence of such co-occurrence restriction patterns.

\subsection{The question arising from the contextual analysis}

As established in the contextualization of Indus inscriptions done in Article_19, Indus inscriptions were used to convey messages related to certain commercial activities and the associated bureaucracy, where metrology and standardization played an important role. Rather than repeating the contextualization again in this article, a mind-map-like graphic summary of the arguments that leads to such a conclusion is depicted in Fig. 6 of this article.

Since Article_19 did not want to venture into the semantic analysis, it did not try to explore the nature of these commercial and bureaucratic tasks prevalent in IVC that needed the inscribed seals, and tablets. But this semantic study needs to answer the following question:

Question-10: What was the specific nature of the commercial and bureaucratic activities that used the Indus inscriptions?

\section{The hypotheses explaining certain semantic aspects of inscriptions}

The answers to the above questions are so intertwined with each other, and touch so many layers of evidence, that rather than going deeper into each hypothesis sequentially, it is convenient to first state the hypotheses without rationalising them, so that the reader can build a mental outline of the proposed semantic model. Next, each hypothesis would be extensively discussed with due substantiation.

Hypothesis-1: The subject matter of Indus inscriptions mostly revolved around recording the collection of certain standardized taxes, tithes and licensing-fees to control the production and trade of various merchandises in the commercially thriving settlements of IVC. The sealimpressions marked on packed bales of goods endorsed that the applicable tax/tithe for those goods were already paid, and the merchandises could be transported to their destinations, just 
as the customs and excise departments in our modern world stamp commodities after their appropriate taxes are paid.

Figure 6. A graphic summary of the arguments that identify the inscriptions as messages used in formalized data-carriers used for commercial and related bureaucratic activities.

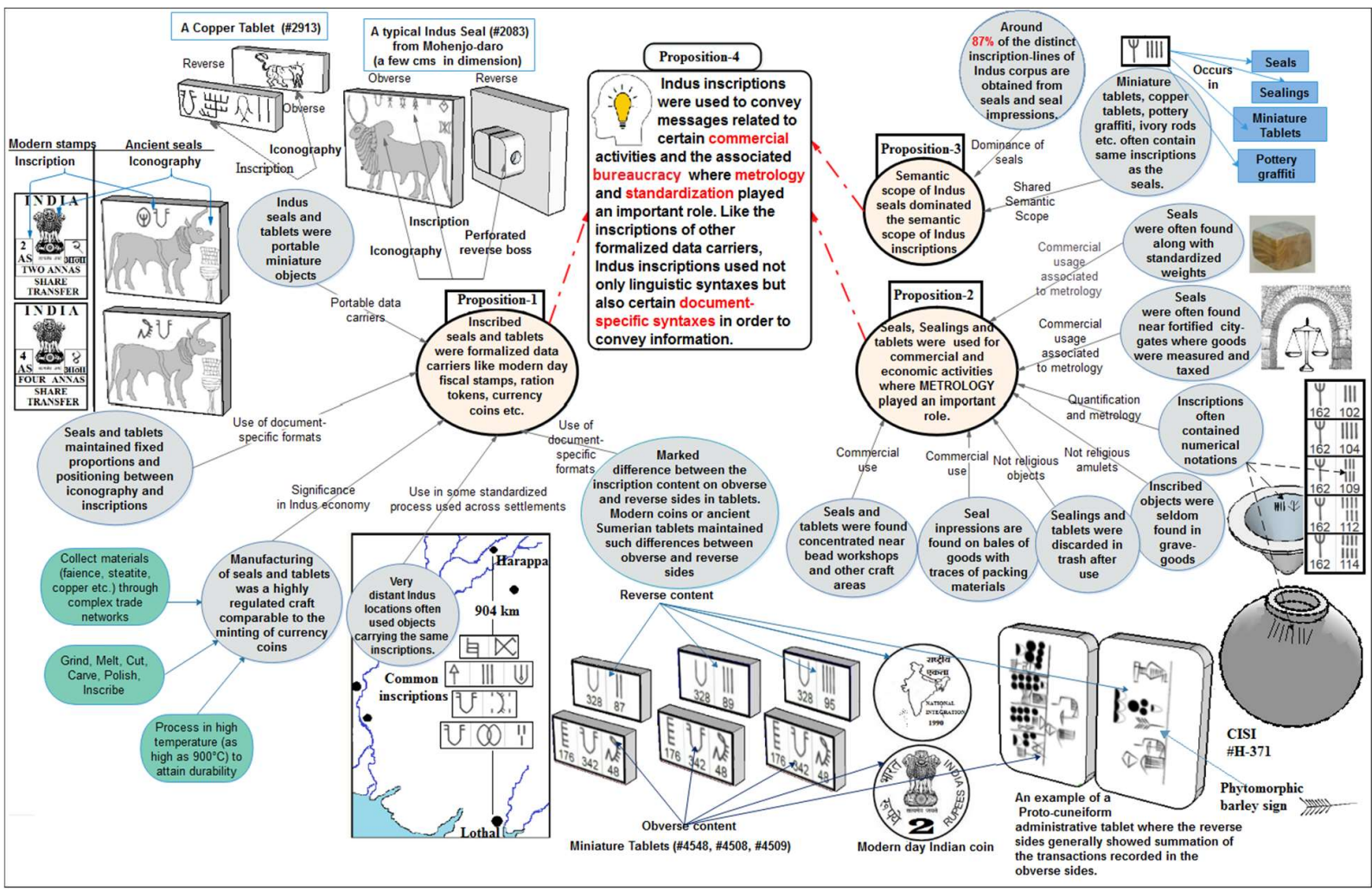

The inscribed tablets and certain inscribed seals might have been used as "commercial licence" or "trade licence" documents so that the owners of those seals and tablets could continue with their commercial activities. Hypothesis-1 answers Question-10.

Hypothesis-2: The structure of Indus inscriptions contained both document-specific and linguistic syntaxes. Each of the functional sign-classes conveyed different types of information that were needed to record the payment of specific taxes in specific rates, and the context and purpose of the tax payment.

Some such categories of information were:

i) The type(s) of good(s) on which the tax is levied.

ii) The rate of the collected tax along with the measurement unit used to measure the commodity involved. 
iii) The mode of collecting the tax. (In ancient barter-based economies without a mature concept of money, different type of commodities were used to pay taxes, using predefined equivalency rates.)

iv) The type and purpose of the tax (for example, whether the tax is related to customs duty, excise duty, license for maritime trade, or for obtaining a commercial license to sell certain goods in a city-market).

iv) Information about the tax-receiving entities.

In some scenarios, the inscriptions might have contained only a few of these information as the other parts might have remained implicitly understood in the context where the inscriptions were used. Hypothesis-2 partially answers Question-1.

Hypothesis-3: The numerical and metrological signs used in the inscriptions of the seals, sealings, and tablets, signified the predefined tax-rates for specific commodities, while the lexemes qualified by them represented the names of those taxed commodities. Thus some of the numerals possibly denoted certain fractional values, such as $1 / 3,1 / 6,1 / 7$, etc. as the tax rates. Whether the number of strokes of a stroke-sign represented the numerator or the denominator of the fractions, cannot be said. However, when present alone in the rim or body of the Indus pottery, the numerical and metrological signs must have been used as integers signifying the capacity of the vessels or the quantity of the vessels' contents in standard mensural units used in those contexts. Hypothesis-3 answers Question-3.

Hypothesis-4: The CROP-signs signified different types of taxes to be collected for the harvested grains. Since in ancient societies grains were used as the most widely accepted medium of exchange, in certain inscriptions, the CROP-signs also might have signified the taxes paid for other commodities through grains using predefined equivalencies. In pottery inscriptions, the CROPsigns possibly denoted either the actual amounts of grains stored in those pottery vessels, or the capacity of the vessels in terms of storing certain quantities of grains. I also propose that different CROP-signs were used to distinguish different crop-types such as food-crops and fibre-crops and

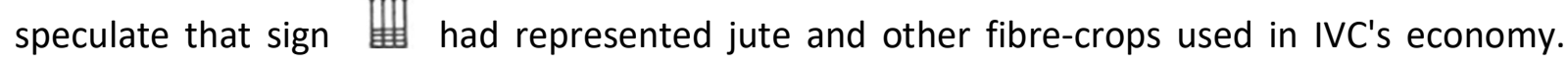
Hypothesis-4 partially addresses Question-6.

Hypothesis-5: The PF1-signs of Indus inscriptions denoted the type of the metrological systems and corresponding mensural units used in the tax collection. Some of the accepted values were volume-based, weight-based, length-based, area based and count-based systems depending on the commodity types involved. Considering the close relationship between the revenue- 
standards and metrological standards in the barter-based economies of ancient moneyless societies, this study proposes that the PF1-signs were eventually used as generalized metonyms of certain broad categories of taxes. Thus, since both CROP-signs and PF1-signs were used to signify certain taxes, both of them could share the terminal positions of inscriptions, which I claim was a document-specific positional convention used in Indus script. Hypothesis-5 addresses parts of Question-1, Question-5 and Question-6.

Hypothesis-6: Since Indus inscriptions were used for controlling trade, the most precious contemporary traded commodities - precious stones like lapis lazuli, cornelian, agate etc., luxury products made of ivory, expensive metals like copper and gold, and beads made of these materials which were much coveted in ancient Persian gulf and Mesopotamia - must have been important taxed commodities, and thus must have been represented through some of the Indus logograms. Since in ancient societies precious stones and metals were often named after their distinct textures and colours, it is important to understand how a logographic script can express abstract ideas like shape and colour using its logograms. Based on various historical, linguistic and graphical evidences, I argue that the shapes and colours of these beads and stones were compared to the colours and appearances of certain animals and plants familiar to the people of IVC, and thus the names of the corresponding trees and animals were used as metonyms of these precious commodities. This pattern can be compared to the popular modern names like "cat's eye stone" or "tiger's eye stone" given to the yellow-green chrysoberyl stones, considering their striking resemblance to the hue of the feline eyes. I claim that some of the logograms with zoomorphic graphemes, resembling birds, fishes and other animals, were used to represent various gems and beads that were manufactured and traded by Indus people. Analysing a plethora of historical and documentary evidences, I trace back the possible ancient words used for "Lapis Lazuli" as words related to "kapautaka". I also argue that the word "mani", or words related to it, was possibly the ancient words used for the beads in IVC. Hypothesis- 6 addresses Question-8.

Hypothesis-7 When used alone in the pre-connective clauses, the numerical signs were used to denote the names of certain taxes that were collected using the numerical rates expressed by those numerical signs. For example, if a tax was collected by taking one-sixth of its corresponding commodity, the fraction $1 / 6$ might be used as the tax's metonym. Using various historical evidences, the study will demonstrate that in ancient India, and in different parts of the ancient world, certain taxes were indeed called by their tax-rate based metonyms. Hypothesis-7 addresses Question-4. 
Hypothesis-8: The PPF-signs possibly denoted the mode of paying certain taxes (the hypothesis is based on the combinatorial pattern of PPFs and the graphical characteristics of the most prominent PPF-sign ${ }^{\Psi}$ ). In ancient barter-based economies where taxes were paid in kinds, the mode of tax-payment (i.e. through grains, livestock, or precious stones) must have constituted important information as it involved calculating the equivalencies between different types of good using pre-defined rates. Hypothesis-8 addresses a part of Question-1.

Hypothesis-9: The post-connective main clauses, which were often used independently as the complete inscription-content in different inscribed objects, possibly signified the information that "tax/tithe was paid for such and such commodity types, using such and such mode and rate". The pre-connective subordinate clauses additionally conveyed the purpose and type of the tax payment, for example clarifying: whether the tax was paid towards the central treasury of some settlements; or to the authority that controlled the entry and exit of certain goods in the city; or to gain the license to execute some specific commercial activities. Hence the PCL signs most possibly signified the "purpose" and "context" of the tax payment, or denoted the tax-receiving entities. By analysing the graphemes of certain PCL signs, and guessing their symbolic association using various historical and linguistic evidences, this study argues that sign $\hat{\nabla}$ that closely resembles the "Abrus precatorious" seeds, which were the basis of the weight system in ancient India, possibly represented "treasury", and the wheel-sign possibly represented some royal or oligarchic authorities who were the recipients of certain taxes. One inference is that the crescentmoon like PCL-sign 9 might have represented some tax or licensing fee which had to be collected on a specific time interval, monthly or yearly. Another, even a more plausible, supposition is that sign 9 , which closely resembles ancient IVC boats, might have signified taxes collected for maritime treads. The composite inscriptions, with coordinating connective morphemes, where the pre-connective or post-connective clauses were morpho-syntactically similar, both ending with PF or Crop signs, possibly signified two equivalent ways of tax payments, or related taxation equivalencies. However, these coordinative clauses would be analysed in more details in future work. Hypothesis-9 addresses Question-7.

Hypothesis-10: The co-occurrence restriction of Indus signs arose from the mutually exclusive semantic nature of the members of certain sign-classes. For example, if a particular tax was calculated in only volumetric measurement mode, then that specific PF1-sign would only be used in the inscribed seals that record such tax-payments. Thus, the weight-based/length-based measurement units would not be used in that seal. The co-occurrence preferences and collocations seen in Indus inscriptions, are similarly explainable. If a particular commodity is always taxed with a specific rate, then, the LEX-sign represented by that commodity would always collocate with the NUM-sign signifying that tax rate. The collocation $\amalg$ ill is a very good 
example, as the CROP-sign WII always occurs with the specific NUM-sign III. Hypothesis-10 addresses Question-9.

Hypothesis-11: The ENC-signs were used to signify a specific category of taxes. The basicgrapheme of the ENC signs signified the mode of paying the tax, and the 4-short-stroke circumgraph represents the rate of that tax, which possibly uses the numerical 4 as either the numerator, or the denominator, in the fraction denoting the tax-rate.

The hypotheses 2-11 and some of the discussion in the Methods section above, answers Question-2, and confirms that the graphemes of many Indus signs had a close relationship with the semantics of those logograms.

\section{Detailed justifications for each hypothesis stated above}

Though the hypotheses above are numbered in a sequence, while justifying them, they are taken up out of sequence and are grouped together as needed.

\subsection{Rationalisation of Hypothesis-1:}

As Kenoyer explains, in IVC, "Massive mud brick walls surrounded most large settlements and appear to have functioned primarily for control of trade access into the cities. Devices for control of trade, such as seals and weights, are concentrated near gateways and in craft areas located near the gateways or along major streets" (Kenoyer, 2010:109). Analysing the field works of other archaeologists, Wells (2011:87) asserts that, "In several contexts at Mohenjo-daro the distribution of seals are highly correlated to the distribution of Indus weights", since the seals and weights were found together in same houses of Mohenjo-daro and sometimes even in the same rooms of those houses. Studying the reports of Harappa excavations done by Vats in 1940, Parpola too states that, Indus "seals have been found occassionally in close association with weights" (Parpola, 1994:114). In the excavation reports at Gola Dhoro, which was a small fortified Indus settlement thriving in craft production of "shell, semi precious stone, faience and copper", archaeolgist Bhan (2011:340) comments that, "Being a very small settlement it is surprising that the site revealed five inscribed seals", and states that, most probably these seals were "used in trade and transitions by the Indus people". From these scholarly judgements and many more similar evidence found in other excavation sites, it becomes clear that the usage of the seals had very strong correlation with: (i) the utility of the fortified city gates of Indus settlements; (ii) the use of the standardized Indus weights; and (iii) the activites performed in various craft making areas and workshops. Now, as claimed by various archaeologists and historians, both the fortified city walls and the standardized Indus weights were associated with trade regulations and tax/tithe collections. As Kenoyer(2010:117) observes, "recent excavations at Harappa reveal that 
the highest concentration of weights is located in association with gateway areas or in craft production areas, where goods entering the city may have been weighed and taxed. Furthermore, many of the smaller sites such as Allahdino, have only a single set of weights in the middle range of values, while only the largest sites such as Mohenjo-daro and Harappa have one or two extremely large weights". Kenoyer explains these facts by stating that "Tax collectors or village elders in the smaller settlements would have needed only one or two sets of weights to collect tribute in special commodities and produce.", whereas the heavier sets of weights were needed in the larger urban centres which were "well suited for weighing tribute coming from all of the surrounding villages and towns" (Kenoyer, 1998:99). Thus, according to Kenoyer, the distributional characteristics of the standardized Indus weights indicate that the weights were used for tax and tithe collection, not for day-to-day barter activities. Since the archaeological evidence strongly indicates that inscribed seals and standardized weights were functionally correlated, considering that seals are by definition used for some kind of predefined endorsement, I can definitively claim that the inscribed seals were also used for taxation and trade-control.

Other than the evidence involving the correlation of seals and weights, the places where seals were found also strongly indicate their function in trade-control and taxation. The massive city walls found in Indus settlements, as explained by Kenoyer, lacked defensive planning, and were "intended to control the trade and commerce which was the life blood" for the Indus cities. As documented by McIntosh (2008:223), several Indus settlements (Harappa, Mohenjo-daro, Dholavira, Kuntasi, Chanhu-daro, Lothal, Kalibangan, Banawali, etc.) were fortified partially or wholly by brick walls with imposing gateways, where "Side chambers often flanked the gateway, probably accommodating gatekeepers, who could monitor the flow of people into and out of the city" and could "collect taxes or customs dues on goods being brought into or out of the settlement". My study argues that the finding of inscribed stamp seals near these gateways strongly suggests that the seals' inscriptions were pre-designed messages that could record the collection and payment of such toll and custom duties. Such usages of the Indus seals are also found in the context of long distance trade activities of Indus people, in the distant locations of ancient Persian Gulf. Parpola's (1994:114) statement that "Gulf seals and stone weights of the Harappan type were found in remarkable numbers in the houses right next to city gate, where a well and a trough served as a halting place for pack animals" is apt in this context, as these houses were "ancient customs houses convincingly identified on the island of Bahrain", where "the incoming and/or outgoing goods were weighed and stamped by customs". As I mentioned here before, even if written in 4th century BCE, Arthaśāstra has recorded various economic traditions of ancient India, which were practised much earlier than the Mauryan period. In some passages of Arthaśāstra, that describe the responsibilities of the "chief collector of customs and octroi", we find suggestions about setting up the Custom House "near the main gate [of the fortified city] 
facing east or north"; appraising all "entering the city"; allowing dutiable goods "to be sold only after they had been weighed, measured or counted [and duty paid accordingly]"; stationing "four or five customs collectors in each post"; keeping record of such things about merchants as "their names, places of origin, the quantity of merchandise, place of issue of identity pass and place where the goods were sealed" etc. (Rangarajan, 1992:406). These passages provide direct historical evidences about the nature of Indic customs centres, predominantly located near the gateways of the fortified Indus cities, and equipped with seals and standardized weights. In my opinion, the customs centres were possibly equipped with other metrological equipments too, such as earthen vessels and reed baskets of standardized volumes, which because of their perishable nature could not be discovered as part of the excavations, unlike the stone weights and seals that have defied the ravages of time to inform us about their rich lineage. Thus the commercial activity associated with Indus seals were manifestly taxation and trade-control, involving both standardization and metrology.

While certain seals were predictably used to collect customs and toll type dues, others might have been used in excise-type taxes, where the seal owners had to pay fixed amounts to obtain the seals that could be used as "commercial licence" for manufacturing or selling commodities like beads, shell-bangles, copper implements etc. As observed by Possehl (2002:131), unlike the typical stamp seals which were used to make a lot of seal impressions, certain other seals were worn only at edges, with their interior carvings retaining "fresh, crisp" lines, which suggest that these seals "may have been used primarily for visual identification. The seal itself, not the impression, was shown. It identified, or gave some form of legitimacy, to the bearer". In my opinion, Possehl's inference accounts for the unusually high concentration of Indus seals found near the craft areas and workshops, since those seals visually identified their owners as authorized practitioners of specific commercial activities. These seals could also be occasionally used to stamp some package to endorse the package's legitimacy.

Interestingly, certain commercial activities of IVC might have involved different departments of "state-appointed", "city-appointed" or "guild-appointed" officials who collected different type of taxes for the same commodity. One such example is given by Parpola, where around hundred clay labels were found from a "burnt-down warehouse or granary at Lothal", and some of these tags that contained two to four seal impressions were unmistakably "interconnected, linked with each other by shared seal impressions" (Parpola, 1994:113). As per Parpola (1994:113), these kinds of tags were generally "attached to bales of goods, for their reverse sides usually show traces of packing materials such as woven cloth or reed matting". In my opinion, this evidence suggests that, certain packed commodities were taxed in several different ways by differently authorized officials, and each official had endorsed the payment of the respective taxes based on the content of the packaged good, using a separate seal-impression. I compare this situation to a cargo container of modern times that moves through different parts of a country, pays different 
types of taxes in different check-posts, and thus gets stamped and endorsed by different authorities.

Finally, had the Indus inscriptions been used for taxation and trade-control, they must have been used in a standardized manner in different Indus locations. The existence of identical and nearidentical inscriptions engraved on seals, sealings and tablets found in very distant Indus locations strongly supports this hypothesis. As depicted in Fig. 7 below, in certain instances, different seals and tablets used in Harappa, Mohenjo-daro and Lothal were engraved with identical inscriptions, while Harappa was almost 600 kilometres away from Mohenjo-daro and around 900 kilometres away from Lothal. Thus even though scholars have considerable doubts regarding whether there was some centralized "state" operating in ancient IVC, this study can at least argue that there must have been certain organized elite classes, most possibly "merchant clans", who maintained systems of standardized taxation and equivalencies so that the widespread barter-based trade network of IVC, crucial for the manufacturing of various complex commodities, could smoothly operate (Ahmed, 2014:141). Eminent historians contend that these merchant clans were most possibly responsible for producing the "large scale public goods" such as building the city roads, water reservoirs, sanitation systems etc. in their local operating regions (Ahmed, 2014). I claim that these "trade guilds" or "merchant clans" must have collected different types of taxes to bear the expenditure of these public welfare activities, and the seals were used as crucial tools in their administrative machinery. Thus, if a commodity was endorsed (regarding some tax-payment) by a stamp-seal impression issued by the authorities in ancient Lothal, it had to be accepted by the respective authorities operating in Harappa and Mohenjo-daro as well, and vice versa. Thus, although I disagree with Frenez (2018), that the inscriptions signified some "public persona" of Indus bureaucrats by encoding their official designation or affiliation, I completely agree with his incisive observation, that the standardized seals were used "within a hierarchically regulated structure of officially established and liaising socio-economical-and possibly-political" power structures, in the "highly unbalanced oligopoly" that prevailed in IVC for more than six centuries.

Figure 7. Examples of certain identical inscriptions found in distant Indus locations. 


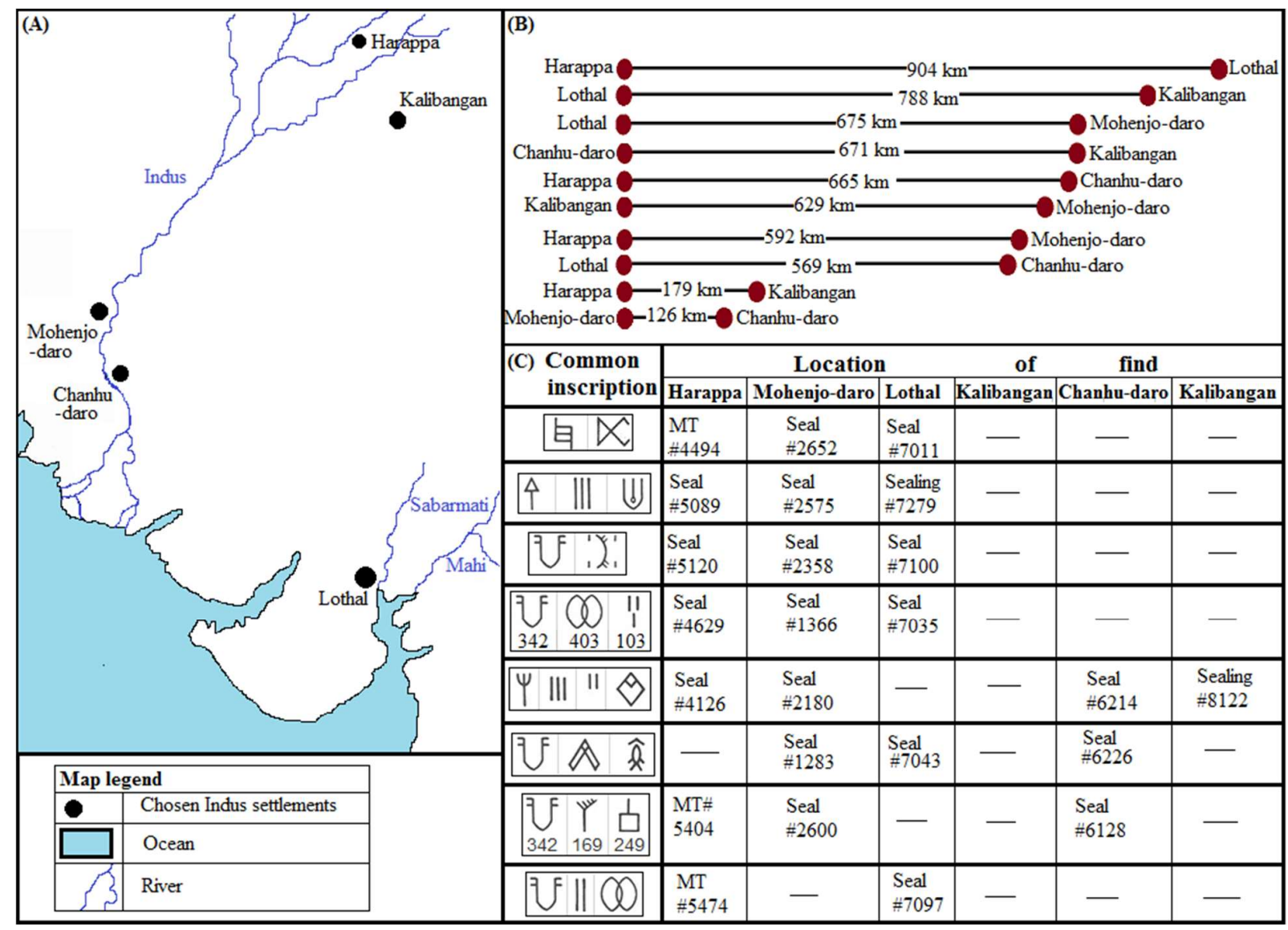

\subsection{Rationalising Hypothesis-2:}

As claimed in Hypothesis-2, a document that specifies some tax rules to record whether those rules were fulfilled in some transactions, should generally mention certain information such as: name of the taxed commodity; rate, type or purpose of the tax; identity of the taxreceiving entity; and mode of the tax collection. Fig. 8a shows a few examples extracted from the excise and customs rates (2016-2017) on import/export of some commodities specified by the Government of India (http://www.cbec.gov.in). Since the mensural units and tax-rates for different type of commodities (e.g. tobacco, cigar, mineral water, and shirting fabric) are bound to be different, they had to be mentioned even in the tax-documents of modern times.

Figure 8. Document-specific and linguistic syntaxes existing in modern formalized data carriers . a. Certain structured information found in modern tax documents; b-c. USA ration coupons and their structural units; $d$. Certain alternative structures found in USA ration coupons. 


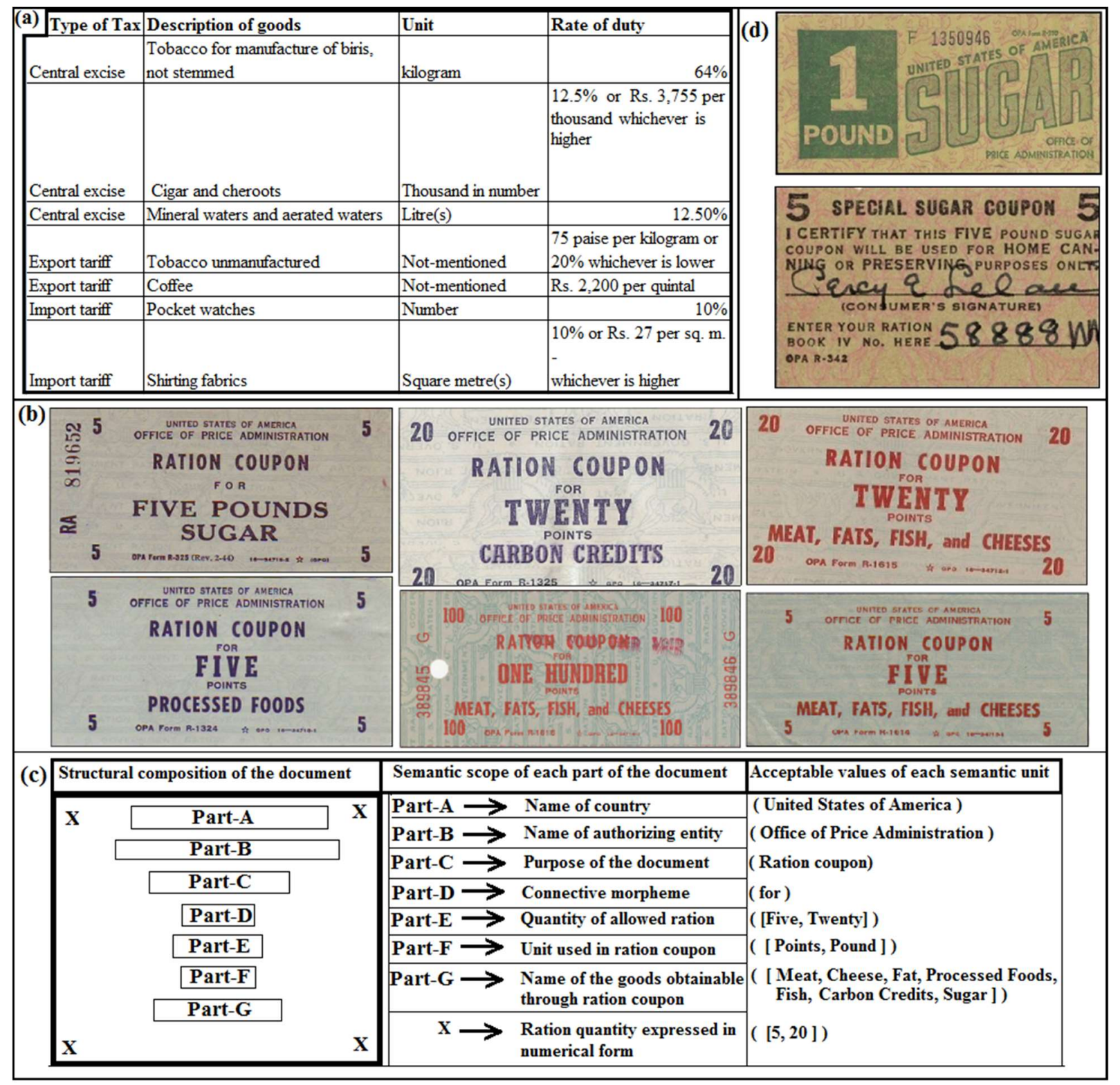

Regarding the claim that different parts of the inscriptions conveyed different types of information, let us have a look at some American ration coupons (as modern formalized datacarriers) issued during Second World War (Fig. 8b). As explained in Fig. 8c, each part of the coupons was designated to encode a certain class of information. Moreover the words used in these parts belong to certain functional-classes, each of which can accept values from specific sets of words. For example, the "Unit-class" (Part-F) would only accept certain mensural nouns ("points", "pounds", etc.), whereas the "Rationed-Quantity class" would only contain numerical nouns of a limited range $(5,20,100$ etc.). Similarly I argue that driven by some domain-specific 
reasons, the numerical signs of Indus inscription could only express quantifications of a standard limited range, while only a handful of PCL-signs suited the semantic scope of the pre-connective constituents in the majority of the composite inscriptions. Moreover, the connective-morphemes used in Indus inscriptions can be characteristically compared to the purposive connective "for" used in these coupons. We also see that the word-members of the "Rationed-Commodity-class" always occurred at the terminal positions of the main information content of these coupons, only because the document-specific syntax of the coupons had used such a format, not because of any linguistic rule imposed on those nouns in English grammar. For example, the phrase "Ration Coupon for Five Pounds Sugar" could be alternatively written as "Five pounds of Sugar to be obtained using this ration Coupon", moving the terminal words "Five Pounds Sugar" to a "phraseinitial" position. In fact, a few such alternative document-specific formats are demonstrated in Fig $8 \mathrm{~d}$, where the rationed commodity is placed in the initial or most prominent positions of the coupon, strongly supporting my point that the positioning of the information units in a formalized data carrier cannot be explained solely based on the grammatical syntaxes used in its underlying language(s). These examples theoretically support my claim that if the Indus inscribed objects were "formalized data carriers", used for controlling commercial activities by endorsing the payment of standardized taxes, tithe and licensing fees, then different parts of the inscriptions must have conveyed different types of tax-related information. Interestingly, the semantic compositionality of the longer Indus inscriptions can also be explained using the examples of Fig. $8 \mathrm{~b}$, where certain coupons contain "Meat, Fats, Fish, and Cheeses" as the rationed goods in PartG. Now, it is theoretically possible to have other coupons, which were for only single items, i.e. only "Meat" or only "Cheeses". But in this coupon, all those informational units got combined, to have a longer Part-G. Similarly, the 13-signs long inscription of Fig. 5, contained several smaller informational units found in other seals and tablets. The subsequent analysis of the nature of different functional sign-groups shall support these claims in further detail.

\subsection{Justification of Hypothesis-3 :}

Looking at the Indus inscriptions, it becomes clear that the NUM-signs and MET-signs occurred in certain fixed patterns before the lexeme signs qualified by them. For example, sign \& was preceded by numerical signs in 159 DILs, among which in the majority of DILs it got preceded by either NUM-sign $\|$ (65 DILs), or NUM-sign $\Psi^{\Psi}$ (50 DILs), whereas the short-stroke numerals III and III preceded \& in 16 and 11 DILs respectively. But the 3-long-stroked NUM-sign || $\mid$ never preceded $\mathcal{k}$, though it regularly collocates with the mortar-pestle sign $[J$ forming the construct III (b). Similarly, the CROP-signs $\Psi$ and $\Psi$ very often occurred preceded by various short-stroke numerals, though they too never occurred preceded by the long-stroked NUM-sign III. Crop-sign III showed an even stricter pattern of almost always occurring with the 3-short- 
stroked NUM-sign III. Thus, the combinatorial patterns of Indus numerals strongly indicate that they were used to signify some standardized quantification values, not to record the random quantities involved in everyday commercial transactions.

The archaeological evidence also indicates the same. Analysing the life-cycle of the inscribed seals and tablets of IVC, it becomes clear that they were engraved with inscriptions in highly regulated workshops (Kenoyer, 2005), long before they got circulated in different Indus locations. So, the inscriptions could in no way be used for recording different quantitative values involved in specific market transactions. They rather recorded certain rules which needed to be followed in the commercial activities of IVC. For example, that the packed merchandise of IVC were stamped by seal-impressions (Parpola, 1994:113), clearly proves that the seal-inscriptions were used to endorse those packages against certain pre-defined legalities.

So, considering that the semantic scope of the inscriptions was related to taxation and trade control, and the NUM-signs were used in a fixed pattern before specific lexemes, this study confidently claims that the NUM-signs signified fixed tax-rates specified for certain commodities, and those commodities were expressed through the lexeme-signs qualified by them. The pattern that only a limited range of numeral signs got used in the inscriptions is explained by the fact that tax-rates are generally expressible through a very small set of numerals. For example, the rates of the newly imposed GST taxes of Indian government (since 2017 AD) largely involves only 4 slabs of $5 \%, 12 \%, 18 \%$ and $28 \%$ tax-rates, and hence are mostly expressible by just 4 numerical values. This claim also explains why certain numerals get used much more frequently than others in the inscriptions. In every complex economy (ancient or modern), it is generally the case that certain tax-rates are applicable to a large number of goods, whereas some others taxes are applicable to only a selected class of commodities. For example, while a large number of products and services fall under the 5\% GST category in modern India, gold and other precious stones was taxed with a special 3\% rate in 2017 and a special $0.25 \%$ rate in 2018 . Similarly certain commodities in IVC might have been taxed with a more common rate, making certain numerical signs abundantly used in inscriptions, whereas certain commodities got taxed using a less frequent rate, and hence the lexemes expressing them were qualified by a more restricted set of numerals.

The numerical signs present in pottery vessels apparently had a different usage. Many of the Indus pottery vessels were made of certain standard sizes, and the numeral signs present alone in their rim or body, quite obviously expressed the capacity of those vessels, or the quantity of their contents. Arthaśāstra has often mentioned use of various certified containers, measuring different denominations of the prevalent metrological standards, such as "kudava " or "prastha", which were used for commodity disbursement (Rangarajan, 1992). 


\subsection{Rationalisation of Hypothesis-4:}

Here I shall explain my claim that the CROP-signs $\Psi, \Psi, Y, \Psi$, etc., which resemble sheaves of grain crops, actually signified harvested seeds and grains, and related taxes. Sheaflike graphemes were universally used as logograms of grain crops. The proto-cuneiform ideogram for barley was also a sheaf-like sign (see right-down corner of Fig. 6), whose graphical similarity with Indus CROP-signs was pointed out by Mahadevan (2006) as well. Since in ancient moneyless societies, the harvested crops were one of the most important sources and modes of revenue collection, they are expected to be frequently present in tax-related documents. This explains why the crop-like signs occurred in so many inscriptions preceded by various numerical and metrological signs. I argue that in IVC, the taxes imposed on harvested grains, or the taxes which were paid through harvested grains, were also named after those grains. In ancient India, such tax names were quite abundant. For example, the Sanskrit noun "dhānya", meaning paddy, also meant "produce of the fields, a share of which was payable to the king or landlord" (Sircar, 1966:91). Moreover, the Sanskrit term "dhānya-varga" literally meant "the grain group", actually meaning "class of taxes payable in grains", which is comparable to the Tamil tax-terms puravunēl, nēl-ayam etc. (Sircar, 1966:91,422). In IVC, such harvest-based taxes named after the common crops, such as barley, wheat etc. must have existed, and the crop-like signs arguably represented some of them.

Since, the CROP-signs had evidently retained certain pictographic features, I shall make another hypothesis that the sign 1 , possibly represented some crop-plant with some water in the crop's base. I further propose that sign "Wy had possibly signified the very important fibre crop jute, which needs plain alluvial soil and standing water, and whose long stems with leaves sprouting only on the upper side of the stem closely matches the logogram used here. Fig. 9 shows certain typical jute stems (9a), suitability of 1 and its repeated projections to represent the closely planted jute stalks partially submerged in water (9b), and the graphical resemblance of the jute stalks used in Pakistan's state emblem with sign Mrey. Moreover, the presence of jute in the national emblems of both Pakistan (the country that hosts many major IVC settlements) and Bangladesh (Fig. 9c-d) proves its importance as a cash-crop even in today's economy. Analysing "a preserved structure of jute on a ceramic artefact from the site of Harappa that is dated to 2200-1900 (cal.) BC", Wright et al. (2012) have suggested that "the identification of a jute textile at Harappa provides new information on textile production during the peak of urbanization in the Indus and should be incorporated into the study of cloth in this region". My study proposes that sign possibly signified not only jute, but also other such fibre crops which must have been very important taxed commodities in IVC economy. Arthaśāstra too mentions certain 
fibrous plants as "valkavarga", and instructs in detail how different fibrous products should be taxed. The short-stroked NUM-sign III possibly signified the tax-rate fixed for such products.

Figure 9. Jute plants (a), Indus sign 10 and its graphic suitability to represent jute (b), similarity of the jute symbols in the state emblem of Pakistan, the country of ancient Mohenjo-daro (c), jute leaves in Bangladesh's national emblem (d).

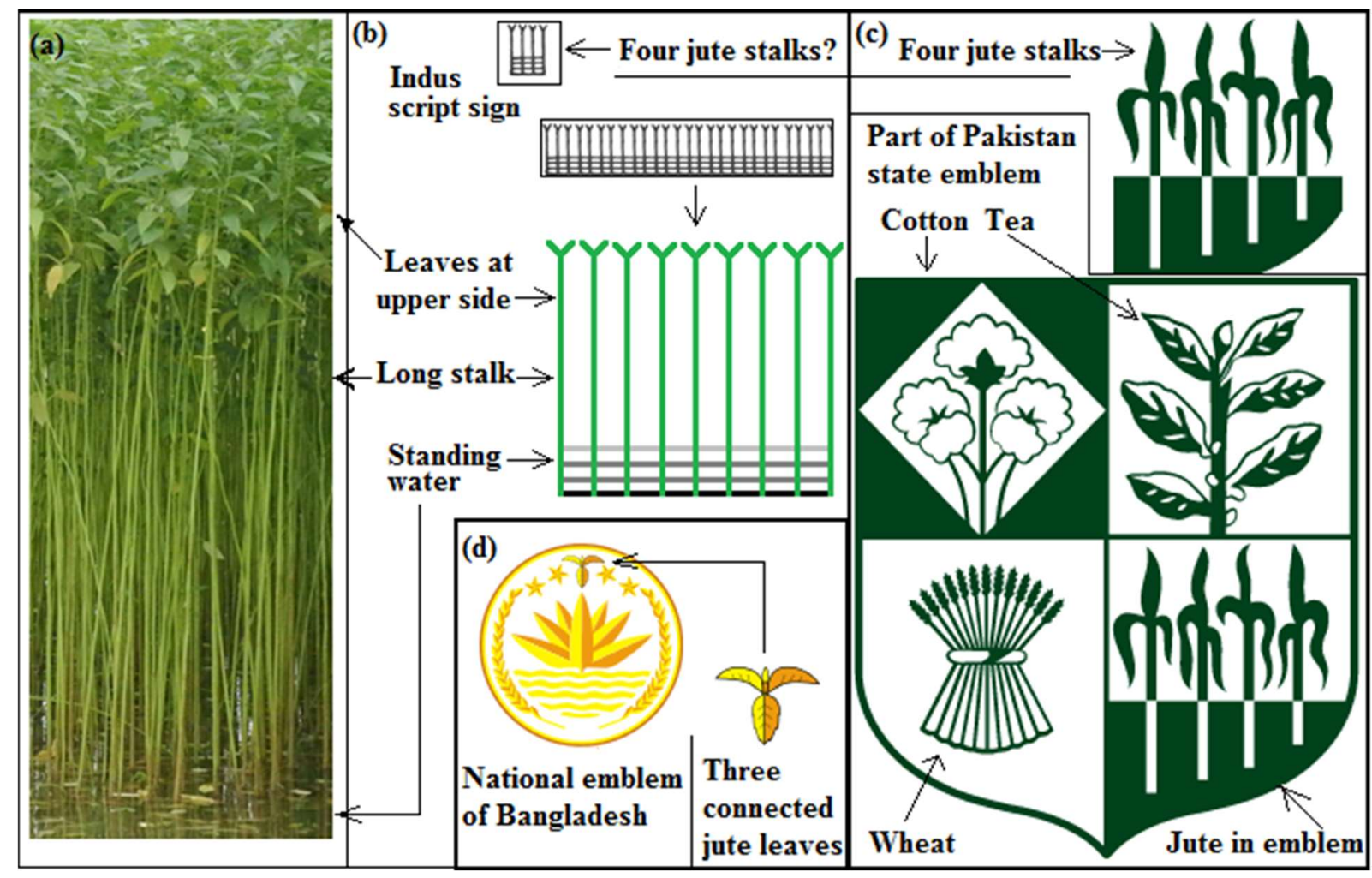

\subsection{Validating Hypothesis-5:}

Hypothesis-5 is built on the graphemic and combinatorial relationship shared by the PF1 and MET-signs, the graphemic feature of MET-signs that semantically associates them with the metrological vocabulary used in ancient India, the close relationship between the revenuerelated nouns and metrological nouns used in ancient barter-based economies across the world, and the tendencies of the metrological nouns to get used across a large geographic region, along with their capability to sustain their meanings for thousands of years.

As recorded by Mahadevan (1977), PF1-sign U', and MET-signs, ' ' ' '"',$U$, and '"') show certain graphemic variations in different inscriptions (see Fig. 10). Now, even a cursory look at those graphemes would persuade us that signs $\mathcal{V}$ and $U$ closely resemble certain rimmed 
and rimless vessels, jars or pitchers. On the other hand, the PF1-sign $\$ \wedge / 8$ unmistakably symbolizes a "load-bearer" pictograph, showing a man holding equal amounts of weight on either side of his shoulder-pole. The PF1-signs $8 \hat{10}$ and $8 / \overline{1}$ are respectively constituted by combining the graphemes of the arrow-like PF1-sign $\uparrow$ and the jar-like PF1-sign $\mathcal{V}$, with the load-bearer grapheme of sign $\$ \times 1$. In some instances, the load-bearer grapheme also seems to resemble a pan-balance. Though Article_19 has identified the MET-signs mainly based on their combinatorial patterns and archaeological contexts, this semantic study will now explore whether the MET-sign symbolisms were semantically connected to the metrological vocabulary used in ancient times.

Interestingly, concentrating first on ancient volumetric units, it is found that almost all the traditional units of volume were named after various kinds of vessels, jars and troughs used in ancient India. As documented in Arthaśāstra, the main metrological units used in its contemporary period for capacity measurement (some used in both weight and capacity measures) were "kuḍuba", "prastha", "āọhaka", "droṇa", "khāri", "kumbha" and "vaha". Interestingly, almost all of these words also mean certain types of vessels in Sanskrit. For example, "droṇa" means "a wooden vessel, bucket, trough" etc., "kumbha" means "a jar, pitcher, water-pot" etc. (Monier-Williams, 1872). While "prastha" and "kuḍuba" /"kuḍava" primarily means particular grain measures, they also signify containers or vessels having those capacities (Monier-Williams, 1872). Interestingly, terms like "drona", and "kumbha" were also mentioned in Rigveda with the same meanings, respectively "wooden trough" and "pot", whereas "khāri" designated "a measure of Soma in one passage" (Macdonell and Keith, 1912). These evidence clearly show that the metrological terminologies prevalent in the Rigvedic era were used in the time of Arthaśāstra as well, and they were semantically and linguistically associated with the names of the vessels used in this era. Moreover, analysing the lexicons of various Indic languages of Northern India, it becomes clear that the word "drona" was used in various regional languages with the same meaning. For example, in Pāli, Prākrit, West Pahāṛī, Kāśmīrī, Kumauṇī, Assamese, Bengali, Bhojpurī, Awadhī, Hindi, Marāṭhī and Sinhalese, "droṇa" and its derived terms such as "dona", "duni" etc. meant either a "trough" or a "grain measure" or both (Turner, 1999). Looking at the weight-based metrological units, we find a very similar situation. The weight-based metrological units frequently mentioned in Arthaśāstra, are "dhāraṇa", "pala" (10 dhāraṇa), "tulā" (100 pala), and "bhāra" (20 tulā). In Sanskrit, "dhāraṇa" means "holding, bearing, carrying" etc., "tulā" means a "a balance, weight, to hold in a balance, to weigh, compare" etc., "bhāra" means "a burden, load, weight, a particular weight, a pole or yoke for carrying burdens" etc. (Monier-Williams, 1872). Even in Tamil,"tulā", "tulāi", "tulām" etc. means "balance" or "steelyard", or some market weight (Tamil lexicon, 1924-1936).

Besides the spatially widespread usage of the metrological terms like "drona", "tulā" etc., their incredible time-travel across thousands of years would also help us to extrapolate whether 
they found use in the Indus era as well. Among the volumetric standards mentioned above, "drona" was one of the most versatile ones, used to measure a wide range of substances.

Figure 10. Graphemic variations of certain metrological and phrase-final signs. Variations of (a) PF1 Jar-sign $\bigcup^{\prime}$ (b) Jar-like Metrological-signs $\bigcup^{\prime}$ and $\mathfrak{U}^{\prime \prime}$, (c) Load-bearer-like signs $8 \times \mathbf{~}$,

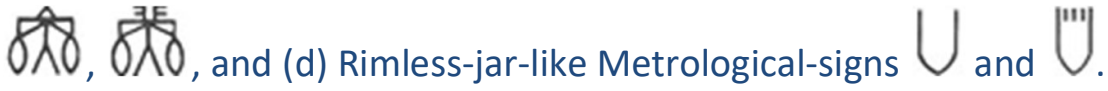

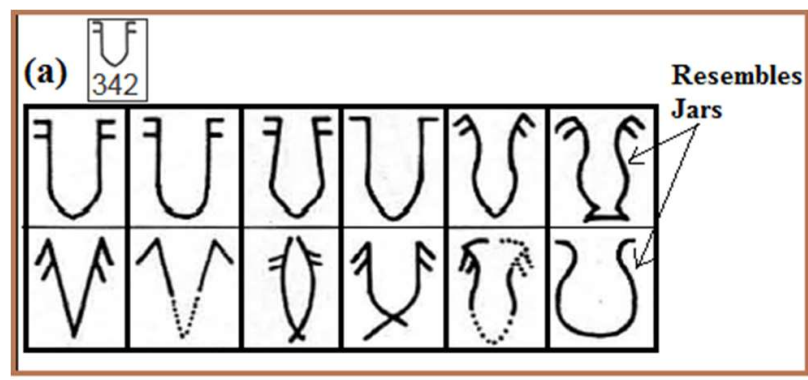

(b) Different allographs

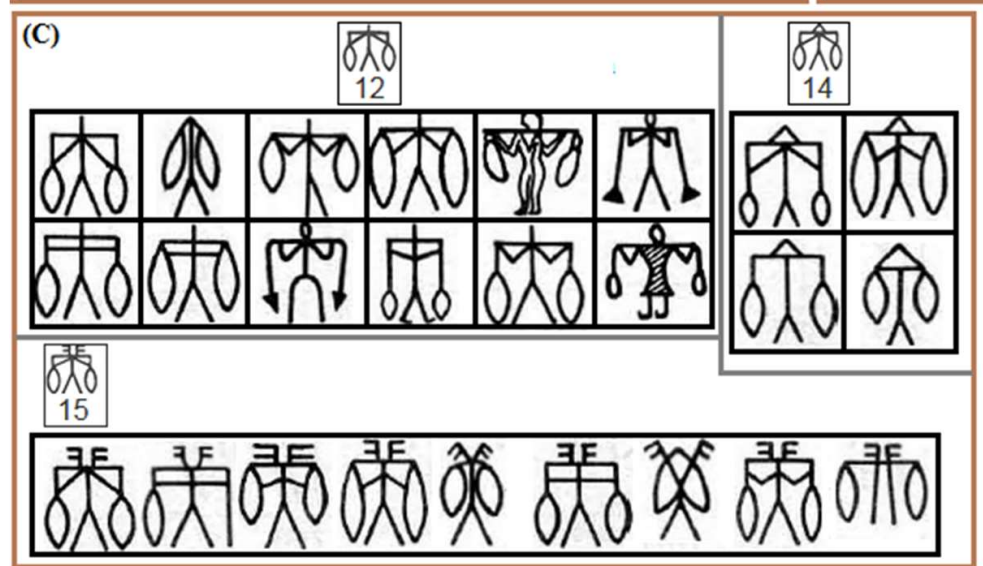

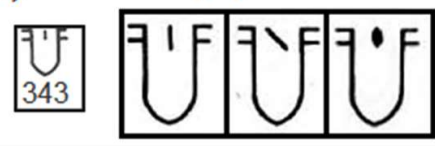
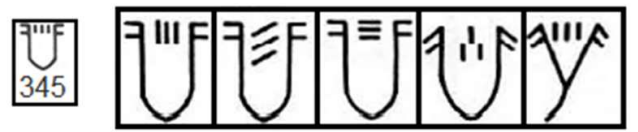

(D)

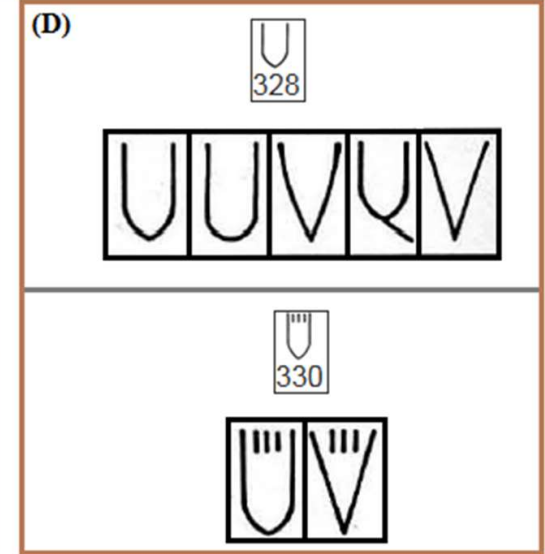

In Vyasa's Mahābhārata, a subsection named "Vrīhi-Drauṇika" tells the tale of a virtuous man "Mudgala" who lived on one "drona" measure of grains for a fortnight (Sarma, 2008). The terms "drona" and "ādhaka" continued to be the main volume-based metrological standards across Northern India. As described in the Paharpur copper plate inscription of Gupta period (AD 479), the units "droṇavāpa" and "āḍhavāpa" were used to measure amount of land-areas which were required to sow "Droṇa" and "Ạ̄̂haka" measure of seed-grains (Pruthi, 2004). Moreover, in Lìlāvatī of Bhāskarāchārya (Taylor, 1816), the relationship described between the grain measures āọhaka, "droṇa", "khārika" and "prastha" remained the same as mentioned in Arthaśāstra, although it was composed almost 1500 years earlier. Moreover the agro-metrological unit "droṇavāpa", was transformed into the colloquial term "doṇ", which was used in different parts of undivided India. Surprisingly, it is used in Bangladesh till date, even though its values in 
different regions differ largely from the value of the ancient unit (Taylor, 1816). In the year 2019, news about the plight of farmers in Bangladesh (see Supplementary-file-1) used "don" as the measure of field, along with other modern Metric units. Considering that the term "drona" could sustain its meaning for more than $\mathbf{3 0 0 0}$ years since the era of Rigveda, despite the influences of various competitive metrological standards including the current international standards embraced by the governments of India and Bangladesh, it would not be illogical to claim that the jar-like metrological units of Indus inscriptions used throughout 2600-1900 BC (1900 BC is just 800 years before the latest dating of Rigveda's composition (Flood, 1996:27-39)), represented either different denominations of these "drona", "kumbha" or "kuduba" standards, or similar volumetric standards etymologically rooted in the words used for "jar", "pot", "trough", "pitcher" or "vessel". Similarly, if the terms "tulā", "bhāra" etc. get associated with weight-based metrological system even now in modern India, both in its northern and southern parts, then the "load-bearer" graphemes semantically associated to the terms like tulā", "bhāra" or "dhāraṇa", arguably had signified weight-based metrology even in the Indus era.

In the same way, the PF1 arrow-sign $\uparrow$, which frequently occurred in identical inscriptioncontexts as the PF1-signs $\mathcal{V}$ or $\delta / 8$, possibly denoted the "reed-based" metrological mode. This hypothesis is based on the fact that in ancient India reed and arrow were often expressed with the same words, and both of them were connected to length-based metrology. According to scholars, the "nālikā" unit, which was mentioned in Arthaśāstra as a measurement of length and time, was used popularly in ancient India as "nala", which was in vogue for measuring land in ancient Bengal (Prasad, 1987). Now both in Pañchatantra and Bhāgavata texts, the expression "nala" was mentioned as a reed, whereas in 500 AD India, "nala" denoted a standard 8*9 reed measure of area (Prasad, 1987). Another length measure, called "daṇ̂a", mentioned in Arthaśāstra, was one of the most usual length measurements of ancient India, whereas according to Atharvaveda, the word "dandana" meant reed or cane (Macdonell and Keith, 1912a). Now, since arrows were made of reeds in ancient times, "śara", a popularly used word for reed in Sanskrit, also meant arrow. Moreover, the word "śarava" is a measure of corn in the Brāhmanas, whereas "śaravya meant arrow-shot" (Macdonell and Keith, 1912b). "Ișu", the usual word for arrow in Rigveda, was also a unit of length measurement (Macdonell and Keith, 1912a). "Tejana", was a length unit mentioned in Rigveda to measure fields, which meant a staff or rod made of reeds, and also meant arrow-shaft in other Vedic texts (Macdonell and Keith, 1912a). Interestingly, "paurușa" was another length-unit mentioned in Arthaśāstra, whereas the word "parușa" appears "to mean 'reed' in the Atharvaeda" and "'arrow' in the Śānkhāyana Śrauta Sūtra" (Macdonell and Keith, 1912a). Moreover, even cuneiform texts bear witness to this close relationship between arrows and reeds in the Indian subcontinent. As mentioned by Parpola(2015), in the Mesopotamian creation-myth clay-tablet "Enki and the World Order", Enki, while decreeing the fate of Meluhha [Meluhha is associated with IVC by several scholars (Gelb, 
1970)], says "may your reeds be great reeds", "Heroes shall [broken, illegible] them as weapons in the battlefields". This text clearly alludes to the traditional use of reeds to make arrows in ancient India. Thus it becomes evident that the words for reed and arrow were used interchangeably in ancient India, and both were used for metrology too. Hence it is quite plausible that the Indus arrow-sign" $\uparrow$ was associated with reed-based metrology.

Thus, the graphemes chosen for the PF1 and MET-signs were evidently related to the ancient metrological-vocabulary. But, looking at the PF1-signs' phrase-level usages, it becomes clear that unlike the MET-signs, they were not directly used to quantify any lexeme sign. Then what was the PF1-signs' role in so many taxation/trade-control-centric Indus inscriptions? The answer lies in the close relationship between metrological standards and revenue standards maintained in ancient urban civilizations, and as before, the historical evidences found from ancient texts of Egypt, Mesopotamia, and India help us find the answer. As explained in Arthaśāstra, in the ancient Indian economy where the concept of money was not yet perfected, to automate revenue collection methods of different commodities, and to avoid repetitive calculation of taxes, the popular metrological units were manufactured in four standard versions. The "āyamāna-droṇa" was the volumetric revenue standard for measuring royal income and it was supposed to hold 200 palas in the grains of másha (Shamasastry, 1929, Kautilya: 51-185). The other drona-standards were 'Trade-measure or public- drona', 'Payment-measure' ("bhājanīya") and 'Palace-measure' or "antahpurabhājanīya", which were respectively 93.75\%, $87.5 \%$, and $81.25 \%$ of the capacity of "āyamāna-drona". Similarly, "different weights were used for automatic collection of the transaction tax" (Rangarajan, 1992:901), due to which, 4 different versions of "Tulā" and "Pala" weights were used for royal revenue, trade, payment and palace measures. Fascinatingly, even in Mesopotamian documents such different versions of the revenue-based metrological standards are found. For example, the Mesopotamian capacity unit "šutu" had different standards such as "tax šutu", "ration šutu","šutu of the palace" etc., and the "tax-šutu" was standardized as 1.5 times of the "ration-šutu" (Powel, 1990). Just like these different versions of "droṇa" and "šutu" measurements, the Egyptian cubit also had a royal version (c. $523.5 \mathrm{~mm}$ ) and an ordinary version (c. $500 \mathrm{~mm}$ ). The "Pharaoh bought goods using the royal cubit and, subsequently sold them using the common cubit", the difference between the measures being equivalent to the "tax paid to the Pharaoh" (Williams, 2014:7).

Based on the evidence above, I propose that the PF1-signs denoted the metrological mode of collecting particular taxes, whose collection would get endorsed by the inscriptions of corresponding seals/tablets. Since the metrological-mode was directly mapped to different revenue-based standards, it must have contained an important piece of information for endorsing the tax-payment. Apart from this, another reason of mentioning metrological modes in tax-calculation could be that the tax-rates for the same tax were different, depending on the 
metrological mode used in the process. For example, as mentioned in Arthaśāstra, the rate of the tax called "Vyājī" was one sixteenth of the quantity of the commodity when measured by cubical units, one twentieth of the commodity when weighed, and one eleventh of the commodities when numerically counted (Sarkar, 2003:96).

Possibly because of all these reasons, the people of IVC correlated the tax-collectors with the metrological modes and tools used by them, and possibly even used the metrological tools as metonyms for the tax-collectors. As documented in Kurudhamma Jātaka, the revenue collector was named "dōṇamapāko Mahamatta", an official "so designated presumably because he supervised the grain-measurement by the cubic measure dōnāa (drōṇā)" (Prasad, 1987:40-41). Jātaka stories mention another official "rajjugāhaka-Amacca", who measured the fields with "rajju" (rope) and "danḍa" (pole/rod), literally "rajjam danḍake bandhitvā", while riding a chariot (Prasad, 1987). Furthermore, in Arthaśāstra, Kauțilya talks about different administrative centres called "saṃgrahaṇa", "kārvațika", "droṇamukha" and "sthānīya", which were supposed to comprise 10, 200, 400, and 800 villages respectively. This study claims that, the derivation of the administrative "dronamukha" from the metrological "drona" quite obviously indicates that the word was rooted in metrology and revenue collection, just as the word for the administrative centre "samgrahana" etymologically derived from the Sanskrit word "samgraha", literally signified "to gather together, assemble, collect" etc. (Monier-Williams, 1872). Intriguingly, Egyptian, Mesopotamian and Assyrian cultures too evince such parallel metonymic metrology. In Mesopotamia, the metrological word "sūtu" or "šūtu", which primarily meant "a vessel", "a measuring vessel of a standard capacity and its volume", "a measure of area based on the quantity of grain necessary for seeding", also meant "(a tax), rent for a field or orchard paid in kind" (Reiner, 1984). Moreover, the word "šutummu" signifies "a storehouse", while the word "šatammu", which is "clearly connected to the storehouse", represented certain revenue collecting personnel in Babylonian and Assyrian context (Johns, 1999). Although Assyriologists do not usually connect the words "šutummu" and "šatammu" to "šutu" yet, I suggest a semantic association between them comparable to that between "droṇa", "Droṇamāpaka" and "Dronamukha". In ancient Egypt too tax-collectors were named after metrological equipment. For example, in a "tax-assessor's journal of the late Middle Kingdom", certain surveyors of the field are called "rope-bearer" and "rope stretcher" (García, 2013), which is a direct parallel to the above mentioned Indian term "Rajju-gāhaka".

All these evidence reinforce my contention that the PF1-signs denoted names of broad tax categories, named after the metrological modes used to collect them. While vessel-like denoted the most popular taxation method collected using volumetric modes, "load-bearer" $8 \times \delta$ signified weight-based taxes, $\uparrow$ denoted reed-measure-based taxes, and the composite 
PF1-signs $8 \hat{40}$ and 810 possibly denoted taxes that could be collected by using both weightbased/reed-based and volume-based/weight-based metrology respectively.

\subsection{Validating Hypothesis-6:}

Since Indus inscriptions were mechanisms to record tax-payment in the bureaucracy of revenue collection and trade control, the taxable trade commodities must have been represented through some of the lexeme signs of Indus corpus. This study argues in the subsections below that: (1) the bird-like Indus logograms must have had some relationship to the widely- travelled word "Kapautaka", that means "pigeon", "a specific blue colour", and "lapis lazuli", in Old Persian language; (2) The fish-signs of Indus inscriptions signified the apotropaic "fish eye beads", exported from IVC to Persian Gulf and Mesopotamia, (3) The word "mani" can be traced to mean beads since the very antiquity of IVC; and (4) Some of the fish-signs were used as a standard equivalency in the complex barter-based IVC economy.

\subsubsection{Precious stones, bird-like graphemes, lapis lazuli and "Kapautaka":}

Archaeological evidences and historical texts of ancient Mesopotamia portray lapis lazuli as possibly among the most valuable exported raw materials of IVC, followed by carnelian, agate, and other precious stones. But if Indus people had to represent the precious stones through their logographic script, what would be the chosen logograms for lapis lazuli?

These stones were generally termed by their characteristic colours in ancient languages. The words for lapis lazuli were 'uqnû' in Akkadian, and 'khesbet' in Egyptian languages; and both the words also meant blue and the colour of sky. Hence to represent such precious stones symbolically by their colours, certain logograms of Indus script should have resembled some wellknown natural objects that contained them. In Arthaśāstra, the colour of the gem "vaidūrya" is compared with the colour of blue lotus and parrot feathers, whereas in Mesopotamian texts the iridescent colour of lapis lazuli was compared to the colours of necks of pigeons and ravens (Moorey, 1999:85). Thus, the bird-like graphemes of Indus script, shown in Fig. 11 below, were evidently good candidates for use as symbols for precious stones of various colours.

Figure 11. Bird-like graphemes of Indus inscriptions. (A) List of bird-like graphemes. (B-G) Examples of the graphemic variations of certain bird-signs and examples of their usages in inscriptions. 
(A)
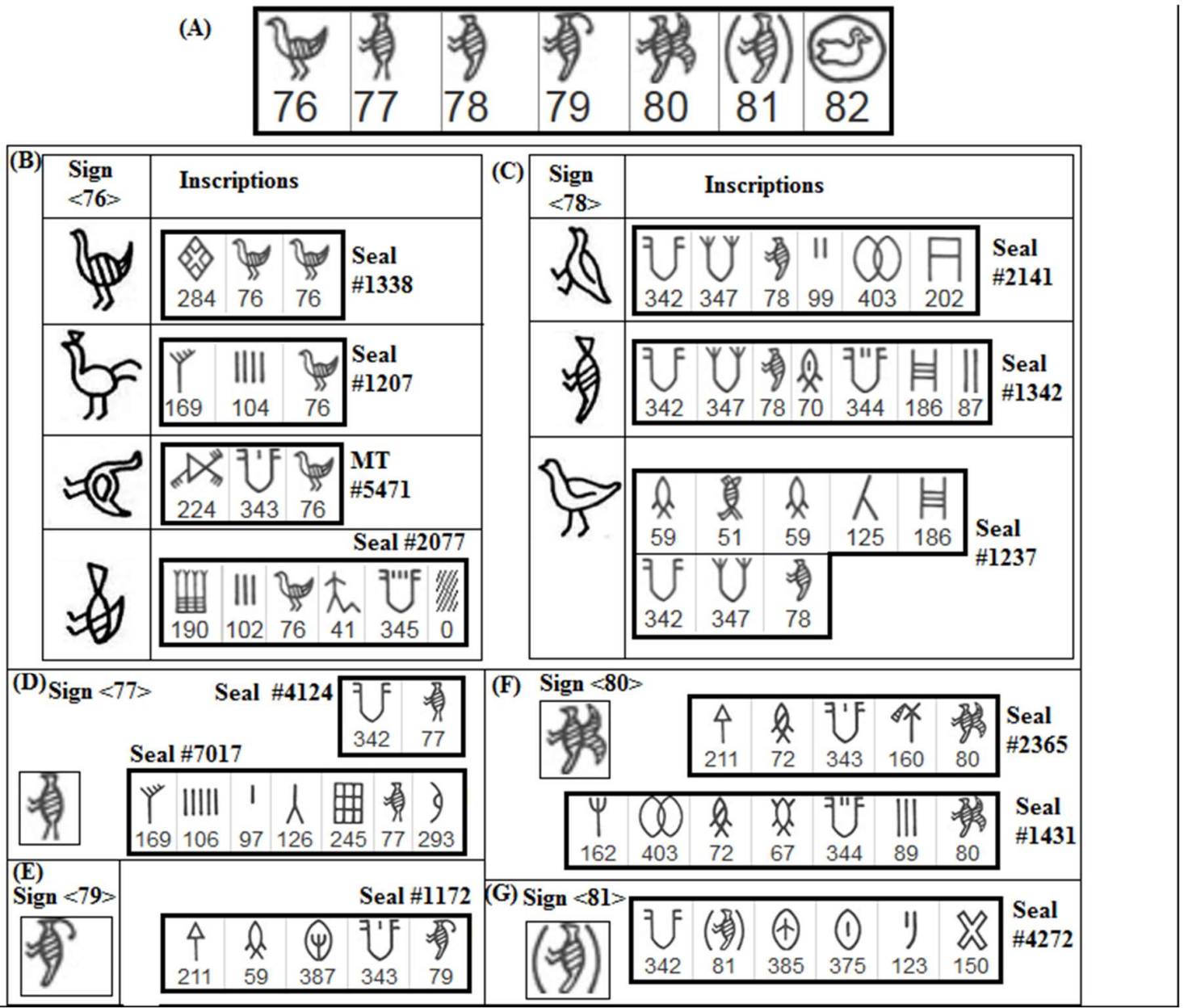

The ultimate linguistic evidence of the semantic association of lapis lazuli with the colour of pigeon comes from the Achaemenid royal inscription of Susa, where King Darius I boasts of the precious materials brought from distant sources of his empire to build his palace. The Old-Persian word for lapis lazuli, brought from "Sogdiana" was "Kāsaka hya kapautaka", which literally meant "stone which is pigeon-coloured". As mentioned by Witzel (1999), the BMAC area languages, like Old Persian, Middle Persian, Khotanese and Sogdian languages, along with Vedic Sanskrit of India, had used the etymologically related words "Kapaut", "Kapauta", "Kabōd", "Kavūta", "Kabōtar" and "Kapot" to signify "blue", "grey-blue" and "pigeon". This linguistic evidence provides the decisive corroborative support to my claim that some of the bird-like logograms of Indus inscriptions must have denoted lapis lazuli and other precious stones. In the examples of Fig. 11, we can see that certain bird-like graphemes had an etched design in them. It is possible that such graphemes represented the much coveted banded agates and etched carnelian stones. 
To explain the rationale behind the usage of similar words for lapis lazuli in otherwise different languages, this study discusses how Khotan, Sogdia and the Indus settlements of North-Western India were directly linked through the lapis lazuli trade. In ancient Asia, the only natural sources of lapis lazuli were the mountain areas of Baluchistan and the mines of Badakhshan. Badakhshan comprises areas of current north-eastern Afghanistan and south-eastern Tajikistan, close to ancient Sogdiana. As documented by art-historians such as Azarpay (1981), the lavish use of lapislazuli in ancient Sogdian paintings was made possible because of the vicinity of the Badakhshan lapis mines to Sogdian territory. As substantiated by Kenoyer (2001a), Harappa was connected to both Baluchistan and Badakhshan through complex trade networks. As documented by Parpola (2015), "A mature Harappan settlement was established beyond the Hindu Kush mountains in north-eastern Afghanistan at Shortugai to control the mining of lapis lazuli" in Badakhshan. The Indus establishment in Shortugai strongly suggests that Indus traders wanted to monopolize the trade of this blue stone, highly coveted in West Asia. On the other hand, Khotan, "the ever important stop along the silk-route", was the "gem market" for far-eastern China, and for Chinese people, lapis lazuli (even though originating in Iran) was known as the "stone of Khotan" (Pal and Richardson, 1983:187). Thus the root of the common words for "blue" and "pigeon" in Sogdian, Khotanese, Old Persian and Vedic Sanskrit language, must be attributed to this widespread trade of lapis lazuli. Since the history of Indus craft-production using lapis lazuli dates back to antiquity $(7000 \mathrm{BC})$, as known from the bead workshops and grave-goods comprising lapis lazuli beads found in Neolithic Mehrgarh (Jarrige, 2008), it would surely not be farfetched to claim that the "pigeon-word" of lapis lazuli had actually originated in Indus valley civilization.

\subsubsection{Beads ("maṇi"):}

Next I come to the famous fish-logograms of Indus inscriptions. As shown in the iconography of the Indus tablet in Fig. 12A, the fish logogram in the mouth of the crocodile is graphically identical to some of the fish-signs used in Indus script. This indicates that Indus fish-signs indeed had a semantic connection to something related to fish. Though from the research of Belcher (1996), we understand the role of various fishes in the subsistence of IVC people, it does not seem tenable that the different fish-graphemes merely represented different species of fish as the major taxable commodities in IVC.

Figure 12. Fish-like logograms in Indus inscriptions. a. Fish iconography and list of fish-like graphemes, b-d. Different combinatorial patterns of fish-signs; e-f. Combinatorial patterns of combined fish and bird logograms. g-i. A complete inscription in a iconography-damaged seal found in the archaeological context of a bead workshop, and various other occurrences of the same inscription sequence. 


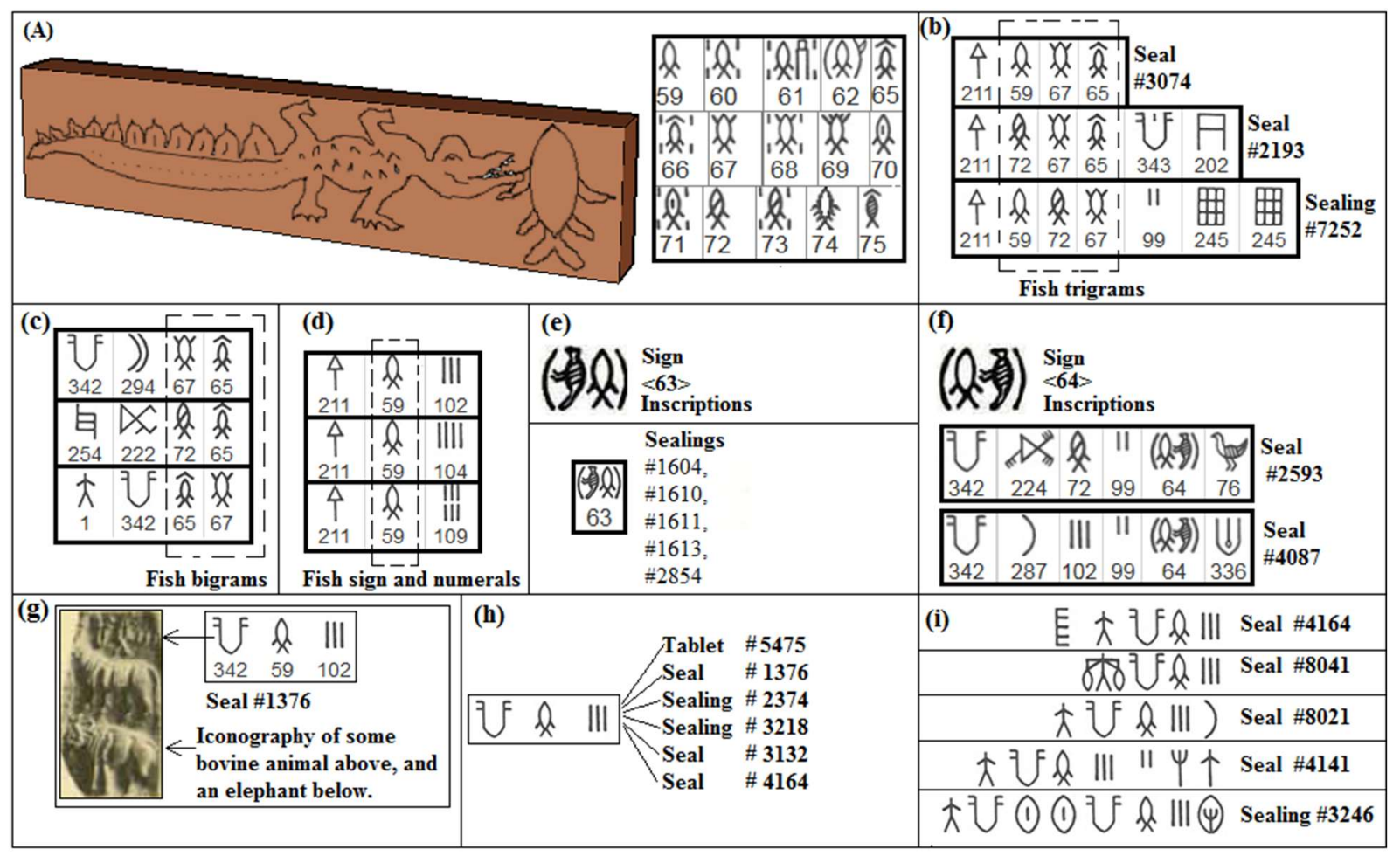

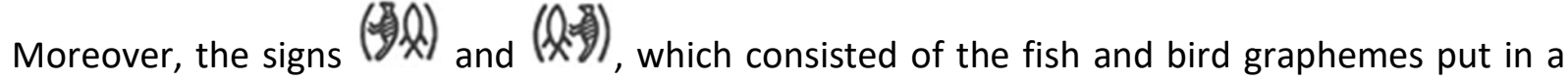
bracket-like enclosure, behaved as compound-lexemes. These signs surely did not signify the tax levied on fish and birds as subsistence items, because these products could not have such a profound effect on IVC economy, so as to be expressed with different dedicated lexemes, superseding thousands of similar commodities that were part of the quotidian life of IVC people. Therefore, to unravel the fish-symbolism in Indus culture, this study engages with the apotropaic words used for the most important craft-commodity of Indus civilization, the beads. Indus beads, which were highly prized commodities in Persian Gulf and West Asia, were among the most specialized craft items and trade commodities of IVC, having a crucial place in IVC's economy. Building on the exhaustive research by Vidale and Kenoyer, Vidale states that "Just to give an impression of the possible cost of an Indus necklace or belt made of long barrel-cylinder carnelian beads, on the basis of experimental replications we calculated that the production of one of these ornaments roughly amounts to 480 days of work by an highly skilled artisan", and claims that, "No wonder that such precious beads were actively sought for and monopolized by the Sumerian elites" (Vidale, 2004:271). Analysing IVC's industry-scale bead-production systems, Kenoyer(2013) comments that, "the use of shell beads with concentric circular patterns that could be interpreted as eyes begins around 7000 BC at sites such as Mehrgarh. Later, during the Regionalization Era or Early Harappan Period, new forms of eye designs were created using natural stones and also carved steatite beads and button seals. The use of eye motifs became more widespread during the urban period and continued to become more elaborate during the 
late Harappan and Early Historic periods". Several texts of ancient Mesopotamia, including the ancient Mesopotamian lexicon "HAR-ra=hubullu", have documented "fish-eyes" ("IGI-KU ${ }_{6}$ " and "IGI-HA"), "Eye-stones" of Meluhha ("NA 4 -IGI-ME-LUH-HA"), and "fish-eye-stones" ("NA $\mathrm{HA}$ ", "NA $4-I G I-\mathrm{KU}_{6}$ ") among the treasured import items of Mesopotamia (Donkin, 1998; HowardCarter, 1986:305-310). Donkin (1998:50) refers to a scholarly consensus that the "fish-eye", "fisheye-stones" and "eye-stones" in old Mesopotamian texts refer to the etched carnelian beads and pebbles of banded agates, which were "cut to resemble closely a black/brown pupil and white cornea" and were imported from northwest India. As documented by archaeologist HowardCarter (1986:305-306), the pedagogical texts taken from tablets of Sultantepe give irrefutable explanation of the etymology of "fish-eye-beads". The texts instruct that, "The name of a stone which looks like a fish-eye is fish-eye stone"; and "The name of the stone which looks like a snake's eye is snake-eye stone". Carter also clarifies that, though eye-stones got their first textual references in the Akkadian version of "The descent of Ishtar", their first archaeological appearance was in the Indus valley trade-port location in Lothal. Even in modern days, eye beads or eye-shaped amulets called "Drsțti" ('Drșți' means eye-sight or glance in Sanskrit) and "Nazar" (eye-sight in Arabic) are prevalent in Turkey and in many other places of the world including India, used as talismans against the so-called "evil-eye". While analysing the "dramatic increase in methods to create eye designs during the Integration Era" of IVC, Kenoyer (2013) states that, this phenomenon "cannot be explained simply as a growth in technical expertise", and hypotheses that Indus fish-eye beads possibly had a similar ethno-historical significance of "protective amulets".

The significance of fish as an apotropaic amulet against evil-eye possibly stems from the fact that since "evil-eye" is supposed to cause "drying, desiccation, withering, and dehydration" in many cultures, "fish are thought to be immune from evil-eye as they are always wet" (Pitts-Taylor, 2008: 111). Another relevant ancient symbolism prevalent among Semitic people of ancient Persia is the comparison of fish-eye to the God's watchful eye, as both never shut, and hence symbolize divine protection (Frankel and Teutsch, 1992). These are the possible reasons why fish are very often portrayed in evil-eye talismans. Interestingly, in ancient Mesopotamian medicine, the "fish-eye stone", "papparminu-stone", lapis stone and carnelian were mentioned as parts of 13 stones that were used as talisman against waning hair, while "pappardilû" and "papparminnu" (interestingly 'mīn' means fish in many Indic languages including Tamil and Sanskrit) stones were prescribed to be used as stone charms against ghost-induced pain (Scurlock, 2014). But pappardilû and papparminu were banded agate stones with one and two white bands respectively (Parpola S, 2007), and as mentioned before, etched carnelian beads and banded agates were known as "fish-eye stones" and "eye-stones" (Donkin, 1998) in ancient Mesopotamia. Thus it is evident that banded agates were indeed used as talismans against evil forces. Even in Christianity, the term "ichthys", meaning "fish", is considered as a very powerful 
apotropaic (Elliott, 2017), and it occurs in various amulets. Intriguingly, excluding the fish fins, the grapheme of the fish-sign \& closely resembles $\propto$, the symbol of ichthys. Finally, a very intriguing Indic traditional symbolism that directly associates "fish" and "eye" is found in the Buddhist Aştamangala signs, where the symbol of two golden fish or "gser nya", represent Buddha's eyes "with which he gazes at the world with compassion" (Reis \& Hibbeln, 2006).

Based on the above evidence, this study affirms that the fish-logograms denoted "fish-eyebeads" or more generally "eye-beads", which having some apotropaic role in the ancient civilizations, were very precious traded commodities, and hence potential taxable commodities of IVC. The different markings in the fish logograms possibly denoted the variation of materials or sizes of these beads, since depending on the material and type of bead the rates of taxes were expected to vary. The combined bird-fish logograms most possibly signified beads made of particular precious stones, and the stones were possibly symbolized through the bird-logograms.

Apart from all this linguistic, historic and cultural evidences, an intriguing archaeological evidence provides a very strong corroboration to the above proposition. Since this study claims that the seals and tablets were used in trade-control, if we find certain seals in a narrow enough archaeological context of a specific shop or workshop that sold or manufactured certain specific commodities, then some of the lexeme-signs present in the seal's inscription can be semantically linked to such commodity names, and the rate of tax associated with them. But in the excavation reports of Indus location, such narrow archaeological scopes where a particular seal can be associated with a particular commodity do not abound, as often different layers of ancient settlements crash down in a particular excavation unit, making it hard to correlate the objects that might have belonged to different temporal zones of IVC. But Marshall (1931:194-195) describes an 8-by-7 feet room found in Mohenjo-daro, part of House-VIII in HR Area, which "yielded the most important find of the season". In this room coexisted silver and copper vases, a copper axe and chisel, various gold and silver ear-ornaments, bangles, diadems, fillets, pins, unfinished ornaments, "a large collection of beads of gold, silver, faience, semi-precious stones, mounted in some cases in gold caps at both ends, and pendants of different materials" along with perforated spacers and hemispherical ornament terminals. Since the unfinished ornaments and a chart scraper are also found, this room is not a personal treasury of a wealthy person, but is surely a jeweller's shop. It is simply not possible that so many linked items landed over the same room from different temporal layers. Thus, when we get a seal in this room, we can easily semantically link it with the jeweler's prized commodities mainly the "beads". Since as shown in Fig. 3g, this seal contains the inscription $\mathcal{U} \&$ III and expectedly sign \& is also there, preceded by a NUM-sign, and followed by PF1-sign $\mathcal{V}$, this study claims that \&ere represented the "beads", for which the jeweller had a trade-license, U represented the tax- 
category as explained before, and the NUM-sign expressed the tax-rate. The next section would take this evidence further to trace out the ancient word used for the fish-logograms that represented beads.

In my quest to find out which ancient Indian word had the semantic association between "eye" and "precious stone beads" or gems, the word "mani" came up as a strong candidate. In the context of analysing Asia's maritime bead trade, Francis (2002) shows how the Sanskrit "Māṇikya", Tamil "Maṇikam", Hindi "Maṇi" and "Māṇek", Malay and Indonesian "manik" and "manik-manik" (plural), are all words meaning "bead", "beads" (plural), and "precious-stone". The ancient Tamil Sangam literature "identifies beadmakers or gem-workers as tirumani kuyinar and mani vinaiar", while the Indo-Iranian word "maṇi" meant "seed, precious-stone, and sperm" (Francis, 2002). As Turner (1999) documents in his comparative dictionary of Indo-Aryan languages, in various languages, such as Pāli, Prākrit, languages of "Kharoșțhī" inscriptions found in Chinese Turkestan, Panjābī, Lahndā, Marāțhī etc., the word "maṇi", along with its close derivatives, meant "bead" and "gem". But both in the Indo-Aryan languages and Dravidian languages such as Tamil, "mani" also meant "pupil of eye" or "apple of the eye", whereas in both Tamil and Sanskrit, "mani" additionally means "amulet" and "a supernatural gem" (Turner, 1999; Tamil lexicon, 1924-36). In Sinhalese, "maṇi" and "miṇa" meant gems, jewels, and precious stone (Clough, 1892), whereas "mina" meant fish, zodiac Pisces and a sort of gem. In Atharvaveda, multiple usages of the word "mani", cover all kind of amulets made from different herbal and mineral products, used as protective charms, counter-witchcraft products, and magical instrument of attack (Bloomfield, 1899). Thus the word "mani" encompasses the meanings of bead, stone, eye and protective amulets, strongly demonstrating the ethno-historical interconnection between these words. The strongest and almost irrefutable linguistic corroboration regarding the ancient origin of "mani", comes from the letters of "El-Amarna Correspondence" (Rainey, 2014), which repeatedly refers to the Akkadian "maninnu" necklaces, which the Mitanni king Tushratta sent as gifts to his son-in-law, the Egyptian king "Nimmureya", in fourteenth century BC. As Parpola (2015) has identified, "The Akkadian word maninnu (with its Akkadian suffix -nnu) contained in this text is one of the few Mitanni Indo-Aryan words that have been etymologically identified: corresponding to Vedic maṇí, "necklace" (Rigveda 1,122,14; and maṇi-grīá-, "wearing a maṇi-necklace on one’s neck")". Thus these "Maninnu" necklaces mentioned in Tushratta's letter were undoubtedly "Manihara" or "bead-necklaces", as each of them was described as containing lapis lazuli beads and other precious stones ("hulalu", "hiliba" etc.) mounted in gold. Hence it is evident that the word "mani", which simultaneously meant "pupil of eye", "bead" and "precious-stone", was used over a long stretch of time across distant geographical locations. With these archaeological and linguistic corroborations this paper affirms that the calquing of this common word in otherwise dissimilar languages is surely traceable to the prehistoric "eye-bead" trade, dominated by the IVC people. 


\subsection{Validating Conjecture 7:}

As mentioned in Question-4, the numerical stroke-signs, which are expected to occur mainly as attributive lexemes, sometimes have functioned as substantive lexemes occurring alone in the

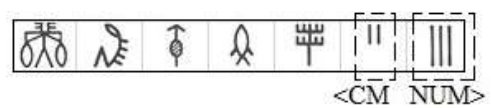

pre-connective constituents (e.g.

in seal \#4229). This study suggests that in such occurrences, the NUM-signs were used as metonyms of certain taxes, levied with a fixed numerical percentage across the IVC settlements, which is why the numerical fraction could be used as their metonyms. A striking Indic example of this pattern is the fraction "șaḍbhāga" i.e. one-sixth, metonym for a royal tax traditionally fixed to one-sixth of the produce. Intriguingly, the term "șaḍbhāgin", which meant "he who has a share of one-sixth", had become "a customary term for the king" in ancient India (Thapar, 2015). Another example of such metonymy is the traditional tax "Chouth", demanded by the Maratha rulers in seventeenth century AD, and levied at one-fourth of the produce (Ranade, 1900). Since in several north-Indian languages the word "Chouth" means a fraction with four in the denominator (ek chauthaee means "one-fourth" in Hindi), it served as a convenient metonym for this tax. Interestingly, even in ancient Mesopotamia, certain taxes were numerically named. For example, the Assyrian (also Akkadian) words "ešertu","ešru", and "ešrutu" meant "ten", "tenth" or "one-tenth", and "tenth part" respectively; and also the tithe (Parpola S, 2007:28). In fact, the English word "tithe", signifying tax taken at one-tenth rate, is itself etymologically rooted in the Old English numerical noun "teotha" which means "tenth" (Clegg, 2003). Thus my hypothesis that the numerals occurring alone in pre-connective parts in Indus inscriptions function as metonyms of certain taxes, is not only concluded from the script's internal evidences, but also gets strong linguistic and historical corroborations.

\subsection{Justification of Conjecture 8:}

As discussed in previous sections, the main characteristics of PPF-signs are their inexorable tendency of occurring immediately before the PF1s (Article_19). Now, since the PF1-signs represented the metrological modes of revenue collection, and in turn metonymically represented the names of associated revenue categories, the PPF-signs closely attached to the PF1-signs are hypothesised to mean the commodity used as the mode of the revenue payment. An important reason behind this hypothesis is the graphical characteristics of the most frequent PPF-sign $Y^{Y}$. In inscription $\left[E \cup 太\right.$ of Seal \#2662, signs $Y^{Y}$ and $\mathcal{V}_{\text {got conjoined to form }}$ sign $Y^{Y}$, which clearly demonstrates the semantic association between the PPF and PF1-signs that could lead to such ligatures. As discussed before, in barter-based economies, harvested crops were one of the main ways to pay revenue, and terms like "dhānya-varga", that literally meant "class of taxes payable in grains", prevailed. Since the most frequent PPF-sign $Y^{\Psi}$ is 
graphically constituted of the most frequent CROP-sign $\Psi$ arranged in a jar-like shape, this study

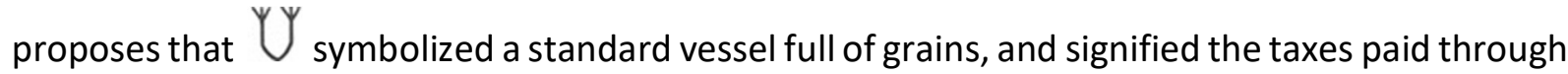
grains as a mode. Two more PPFs, i.e. $Y^{\breve{w}}$ and $\mathcal{U}^{P}$ also use such jar and/or crop related graphemes. Though the other PPF-signs are not individually interpreted in this study, considering that they were functionally similar to $Y$, they too arguably meant some other modes of tax payments.

\subsection{Validating Hypothesis-9:}

This section will validate the hypothesis that claims that the PCL-signs most possibly represented the entities receiving the taxes or the purpose of the taxes, pursuant to delineation of the difference between the semantic scopes of the pre-connective and post-connective constituents of composite Indus inscriptions in Article_19.

The wheel sign : As shown in Fig. 13A, a moulded tablet from Harappa carries an iconography of an anthropomorphic figure strangling tigers. Certain inscribed seals from Harappa had a similar "contest" motif of "a tiger killing hero or deity". Many Indus scholars agree that this iconography is conceptually akin to the Mesopotamian legend of "Gilgamesh", killing lions with both his hands, and that this was a clichéd royal symbolism in West Asia (Parpola, 2015). Interestingly, the sixspoke wheel and the elephant, depicted above and below this "contest" motif respectively, were also stereotypical royal symbols prevalent in ancient India. Using ancient texts like Mahāsudassana-sutta, numismatist Bhandarkar (1921) has explained how "Cakra" (wheel) and "Hastin" (elephant) were among the symbols used to indicate sovereignty in ancient India, which is why they are found so frequently in the punched-marked coins of various kings. After probing several hoards of ancient punched-marked coins, the famous statistician and numismatist Kosambi (1981:5) had commented that, after the solar symbol, "the next commonest mark is some form of the wheel, with (usually) six points of varying design". According to Kosambi, this Sadaracakra is, not a symbol of any deity, but a "representative of the issuing authority, the cakravartin or king". The key to the semantic association of wheel with sovereign power lies in the etymology of Sanskrit words like "Cakravartīn", "Cakrin", "Ekachakra", "Cakradhara", "Cakravat" or "Mahāchakra", each of which means either "emperor" or "sovereign king", or "supreme ruler", or "governor of a province" and each of which is directly etymologically associated with the meaning of "Cakra" or "Wheel" (Monier-Williams, 1872). Interestingly, a rare Indus logogram occurring in $\mathrm{E}$ 颣 $\mathrm{A}$ ) has a similar pictographic representation of a man, where a man is apparently riding two wheels, thus possibly a two-wheeled cart. 
Figure 13. Graphemic and combinatorial features of selected pre-connective lexemes $(A)$ The wheel iconography in an Indus tablet; (B) Wheel symbol in a punched-mark coin of Indo-Greek king Menander; (C) Wheel-like logogram occurring as pre-connective lexeme; (D-F) Resemblance of sign $\$$ with the seeds of Abrus precatorious. (G) Use of sign $\widehat{V}$ in pre-connective lexeme. (H) Egyptian Crescent moon

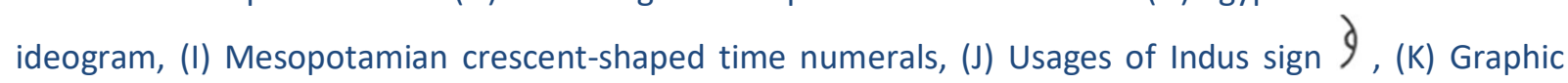

(B)


Fig. 13B shows the iconography (not the inscription) on one side of a punched mark coin of IndoGreek king Menander, where the wheel was used as a royal symbol. Several punch-marked Mauryan coins of $400 \mathrm{BC}$, with "cakra" symbol, also "carry a peacock-on-arches", where the "Cakra" symbolizes royalty and the peacock denotes "Maurya", the name of Chandragupta's dynasty (Kosambi, 1981:26-27).

Thus, this study proposes that like the "Swastika" symbol, this "cakra" symbol also was very ancient, and it denoted "royalty" or "sovereignty" even in Indus age. Whether the six spokes of the wheel symbol alluded to the six expected qualities of sovereign authority (sadguna) that might have been part of ancient Indus philosophy, or to a more materialistic symbolism about the standard one-sixth royal share of produce (see "șaḍbhāga" in discussion about Hypothesis7), cannot be definitively said without further future research. However, the inscriptions shown in Fig. $13 \mathrm{C}$ are argued to have signified different types of taxes payable to some sovereign king, or religious authority, or some equivalent oligarchic committee, functional in the IVC locations.

Sign $\hat{\nabla}$ : Sign $\hat{\nabla}$ is very frequently used in identical inscriptional-contexts as the wheel-sign (compare Fig. $13 \mathrm{C}$ and Fig 13G). Hence sign $\widehat{\nabla}$ should be functionally homogeneous with respect to sign $\bigotimes$, and thus should signify a tax-receiving entity or the purpose of paying certain taxes. Here I make a proposition that sign $\vartheta$ signified "treasury" as a tax-receiving entity. I justify and substantiate this apparently radical proposition below.

As demonstrated in Fig. 13D-G, the graphemes used for $\vartheta$ closely resembles a twodimensional representation of the seeds of "Abrus precatorious", commonly known as "guñjā", "raktikā" or "kṛșnala" seeds. Now, as discussed before, the weight of the " guñjā" seeds served as the basis of the weight system used in IVC, and it continued to be so in the Vedic age, the Mauryan age, and far beyond. Intriguingly, many of the coinage standards used in ancient India in various times were not only based on the weight of "guñjā" seeds, but were also named based on the names of these seeds. As explained by Bhandarkar, in Taittiriya-Brahmana, the passage "kṛșnalam kṛ̦̣nalam vājasṛ̂dbhyah prayacchati", which means "he gives a kṛ̦ṇala to each racer", shows beyond doubt the use of the name of "kṛsnala" seed as a particular gold coin (Bhandarkar, 1921:60). Similarly, the "kākaṇa" or "kākiṇī" coins, which were so well known in ancient India, also were based on names of "Abrus precatorius", as the plant or its seeds too were called "kāka", "kākiṇī", "kākanantī" and "kākaṇantikā" (Monier-Williams, 1872). Just like "raktikā" or "ratti", the terms "kākinī", "kākaṇika" and "kāka" were also widely used as weight standards in ancient India for thousands of years, especially related to the coinage standards or money (Bhandarkar, 1921; 
Monier-Williams, 1872). Interestingly, in Telugu language a common word used for Abrus Precatorious is gurigiñja (Brown, 1903), which is evidently etymologically related to the word "guñja" present in Sanskrit, and it is difficult to say whether the words had ancient Para-Mundic/ Para-Astro-Asiatic, Proto-Dravidian or Old Indo-Aryan etymology. However, since the Telugu word "gimza" or "ginza" means seed or grain in general (Brown, 1903), a more ancient non-IndoAryan etymology might have been more plausible in this case. In Tamil, a common word/root used for Abrus precatorious seeds is "kunri" (Tamil lexicon, 1924-36). Interestingly the "cinna" coins (Telugu "sinna") which were Canteroy fanams, a popular coin-system in South-India, Mysore, were based on the standard weight of guri-giñja seeds, whereas the Tamil weights "mañjāọi" and "kalañju" were based on "kunni-mani", and were used to weigh gold (Sircar, 1966). In fact, another Tamil word used for guri-ginja is gundu-mani, whereas gundu in Telugu means "a weight (stone) for scales" (Brown, 1903). Similarly, kalañju was also a Tamil name of a gold coin of 32 rati or guñja weight. Now, since "guñjā" seeds have played such an important role in the weight and coinage system of ancient India, especially as the main unit for measuring precious stones and gold, it seems logical to investigate whether terms related to "guñjā" were also used as a metonym for some tax-collection entity in ancient Indian languages. A parallel evidence of the administrative unit "dronamukha" related to the metrological unit "drona", as discussed above, is quite encouraging in this context. As before, this hypothesis too gets a linguistic corroboration. As documented in dictionaries of Sanskrit (Monier-Williams, 1872), Sinhalese language (Clough, 1892), and Bengali (Carey, 1981), the word "gañja", that means "treasury", "a jewel room", "a place where grain \&c. is stored for sale", and "a mart" etc. also signified a "plant bearing Olinda seed" or "Abrus precatorious". The etymological root of "gañja" is quite ancient among Indic languages. The Old-Persian and Middle-Persian languages used the words "ganza", "ganzavā", "ganda", and "ganja" to mean "treasure", and "ganzapā", "ganjwar", or "gandabara" to signify "treasurer" and "treasury-protector" (Tavernier, 2007). Interestingly, the famous Mahasthangarh inscription of 300 BCE found in Bangladesh records a need of "filling up of a royal treasury at Pundranagara with ganda and kakini (gamdaka and kakanika)" coins (Ghosh, 2005). Now, the word "gandaka" directly alludes to the Old-Iranian word "ganda" for treasury, whereas it was a very popular coin prevalent in certain parts of ancient India. On the other hand, as mentioned before, "Kākin̄ī" was an ancient weight, and coin, which was also synonymous to the Abrus precatorious seeds. Thus the ancient word for "treasury" had a strong etymological connection to the words used for "guñjā" seeds, reinforcing my hypothesis that, the guñjā-seedlike graphemes, which are functionally homologous with the wheel-symbol signifying some sovereign authority, meant things like "central treasury" or "royal treasury" in Indus inscriptions.

Sign $9:$ 
This article suggests that PCL-sign 9 , which resembles a "crescent-moon" (Mahadevan, 2011), could have signified either taxes payable at a specific time of the year, or some maritime trade related tax. As documented by Egyptologists, and depicted in Fig $13 \mathrm{H}$, the determinative sign that signified "moon" and "month" in Egyptian Hieroglyphic texts, is graphically identical to sign $?$ (Budge, 1920:40,530). The Egyptian crescent moon sign was a part of the symbol for the moongod "Khensu", and was used as determinative sign in various month-related words (Budge, 1920:40,553). The symbol used for Khonsu looks like a boat, possibly because as a god of transitional moon, Khonsu was known as "he who crosses the sky in a boat" (McKoy, 2009). The Mesopotamian $U_{4}$ system for time numerals (Nissen, Damerow, and Englund, 1993) is also graphically identical to the Egyptian moon-sign and Indus sign 9 . Interestingly, in Sumerian lexicon too, "month" and "moon" were synonymous, signified by the words "itud", "itid", "itu", "iti" etc., while the $U_{4}$ sign system was semantically associated to moon, and the calendrics of day, month and year (Halloran, 2006). Hence, crescent-moon sign was evidently a natural ideogram for lunar months.

Interestingly, certain ancient taxes were closely associated with certain months of the year. For example, in Old Persian calendar, the fifth month called "Dṛnabājiš" meant "harvest-tax month" (Tavernier, 2007) or "withheld-tax month" (Cameron, 1948). Now, like the ancient Mesopotamians and Egyptians, ancient Indians too maintained a lunar calendar with a lunar year of 354 days, and according to Arthaśāstra, the end of the fiscal year was the full moon day of the month "Āṣăḍha". Thus, the moon-like sign $\partial$ could have signified taxes that were levied in some specific lunar months of the year.

An alternate and plausible signification of 2 could be related to maritime trade tax, since as shown in Fig. 13K, the iconographies used for Indus boats with a central hut, were graphically akin to the boat-like grapheme of sign 9 . In Arthaśästra, many such taxes related to maritime trade are mentioned. For example, the "superintendent of ships" needed to collect: tolls from merchants in port-towns; one-sixth of the haul from fishermen for their fishing licence; sailingfees from passengers and traders who uses the king's ships; and a fixed-tax from people residing in fortified settlements near oceans, rivers and other important water bodies (Shamasastry, 1929). Thus, maritime trade related taxes must have played a crucial role in the tax-related Indus inscriptions, and could have been expressed through the boat-like $\partial_{\text {sign. }}$

$\operatorname{sign}$ W: 
The sign 1 is another PCL-sign that occurs in very similar inscriptional contexts as other PCLs (Fig. 13L), and just like 9 demonstrates a special affinity towards the CM-sign V. As observed by Mahadevan (2006), Indus-sign graphically resembles the Sumerian "road-sign", whereas Indus-sign and resembles the ideogram used in Egyptian hieroglyphic script to represent city/town (see Fig. $13 \mathrm{M}$ ). Since the road-like sign $\$ is functionally very similar to $)$, whose plausible semantics was associated to maritime trade or some month-based tax, $\mathbb{W}$ might have signified some "road-cess" kind of tax. Interestingly, in Arthaśāştra, the road-cess "vartani" was twice mentioned along with the ferry toll "taradeya" (slokas 2.16.18, 2.35.12), which is a type of maritime tax. In Mauryan period, the road-toll was to be paid for all goods entering the state, collected by the officers of the boundary (Prasad, 1987:91). As documented in Arthaśāştra, the type of revenue items collected at the level of a fortified town (durga) were classified as "śulka" (Prasad, 1987:78), . I propose that sign possibly signified a fortified town ("durga") as its grapheme could aptly represent 'cross-roads enclosed by a wall', and the sign possibly signified a royal/oligarchic authority of the fortified town, as it has the sign enclosed inside the grapheme of . As discussed before, since certain Indus inscriptions have encoded information related to trade-licenses, the shop-owners who were authorized to operate within the market areas in the fortified Indus cities, must had to pay special taxes for their privilege. Thus, it is proposed that the signs and have denoted certain taxes paid to such entities (see Fig. 13M-N).

\subsection{Rationalization of Hypothesis-10:}

Since Hypothesis-10 has been sufficiently explained when stated, I do not discuss it here in further details.

\subsection{Rationalization of Hypothesis-11:}

Since the PF1-signs were used as metonyms of the metrological modes of tax-payments, and thus as metonyms of broad tax-categories, and the pre-phrase-final positions were often used to signify the commodity used for the tax payment, considering the script-internal evidence that the ENC-signs replace the meanings of their basic signs, and the following PF1-signs (Fig. 3e), I propose that the basic graphemes of ENC-signs were supposed to signify the commodities used for the tax payment, and their 4-stroke-circumgraphs were possibly signifying the numeral "4", that was used in the fraction representing the special rate of certain taxes. This is why, none of 
the PPF-signs precede any ENC-sign, and none of the PF1s follow them, as the ENC-signs encompass the functionalities of both PPFs (mode of tax-payment) and PF1s (tax-categories).

\subsection{A brief discussion of the iconographies present in the seals and tablets:}

Though I have limited the focus of this study mainly to the inscriptions, not the iconography present on the inscribed objects, iconographies too played a vital part in the information content of these "formalized data carriers". Unlike many scholars, who have proposed that the seal/tablet inscriptions contained the names of the seals' owners or issuers, this study argues that the inscriptions mostly contained information about taxed commodities, tax-payment modes, taxcategories, and tax-receiving entities. But, there must have been a way to identify the issuing authorities of these seals and tablets, in order to establish their authority in the contexts of related transactions. This study argues that the iconographies were actually used for this purpose. Most of the Indus iconographies are animal-centric, depicting bulls, unicorns, tigers, elephants, crocodiles, and various anthropomorphic figures. Interestingly, certain ancient Indian tribes were actually named after animals. For example, the Vedic texts refer to tribes or people called, "Mahavrșa" (big bull), "Aja" (goat), "Matsya" (fish) etc. (Macdonell and Keith, 1912 a,b). Thus, these animal-centric Indus iconographies arguably denoted the "guilds" or oligarchic authorities that issued the inscribed seals and tablets. Since the iconographic symbols such as the "unicorn" were found in different stratigraphic layers of Indus locations (spanning over a long time period), and in far-flung Indus locations, it could not have signified a single king, chieftain, or a single royal family. Moreover, the existence of several seal-impressions on single sealings, sometimes having different iconographies for each seal (Sealing \#1625 has 3 seal impressions with separate iconographies of bull, unicorn and tiger), proves that the issuing authorities of each seal had some agreement with one another, and hence the issuing authorities are more likely to be symbiotic "merchant guilds" rather than competing royal families. This forms the basis of my hypothesis that the iconographies represented guilds or oligarchic authorities. Another strong corroborative support of this theory comes from the punch-marked coins of pre-historic and early-historic era, where animals like "lion", "tiger", "elephant", "bull", "boar", "peacock", etc., functioned as insignias of different clans and dynasties.

\section{The "reading"}

\subsection{Examples of a possible reading for a small set of related inscriptions:}

This section is the culminating point of my structural and semantic analysis done so far, where, using the insights obtained in the analyses, I try to "read" a small number of inscriptions. Since 
many Indus signs are yet to be semantically interpreted, and "reading" a good number of inscriptions needs a lot more future research, I shall limit my reading attempts to a minuscule set of inscriptions here, just to make the point that, when the functionalities of the functional sign classes are known, it is possible to guess the meaning of the complete inscriptions using the meanings of smaller constituents. As shown in Fig. 14, six 4-signs long composite inscriptions, each starting with PCL-signs and ending with CROP-signs, containing different NUM-signs preceding the Crop-signs are analysed.

Figure 14. "Readings" messages of a small set of Indus inscriptions. 


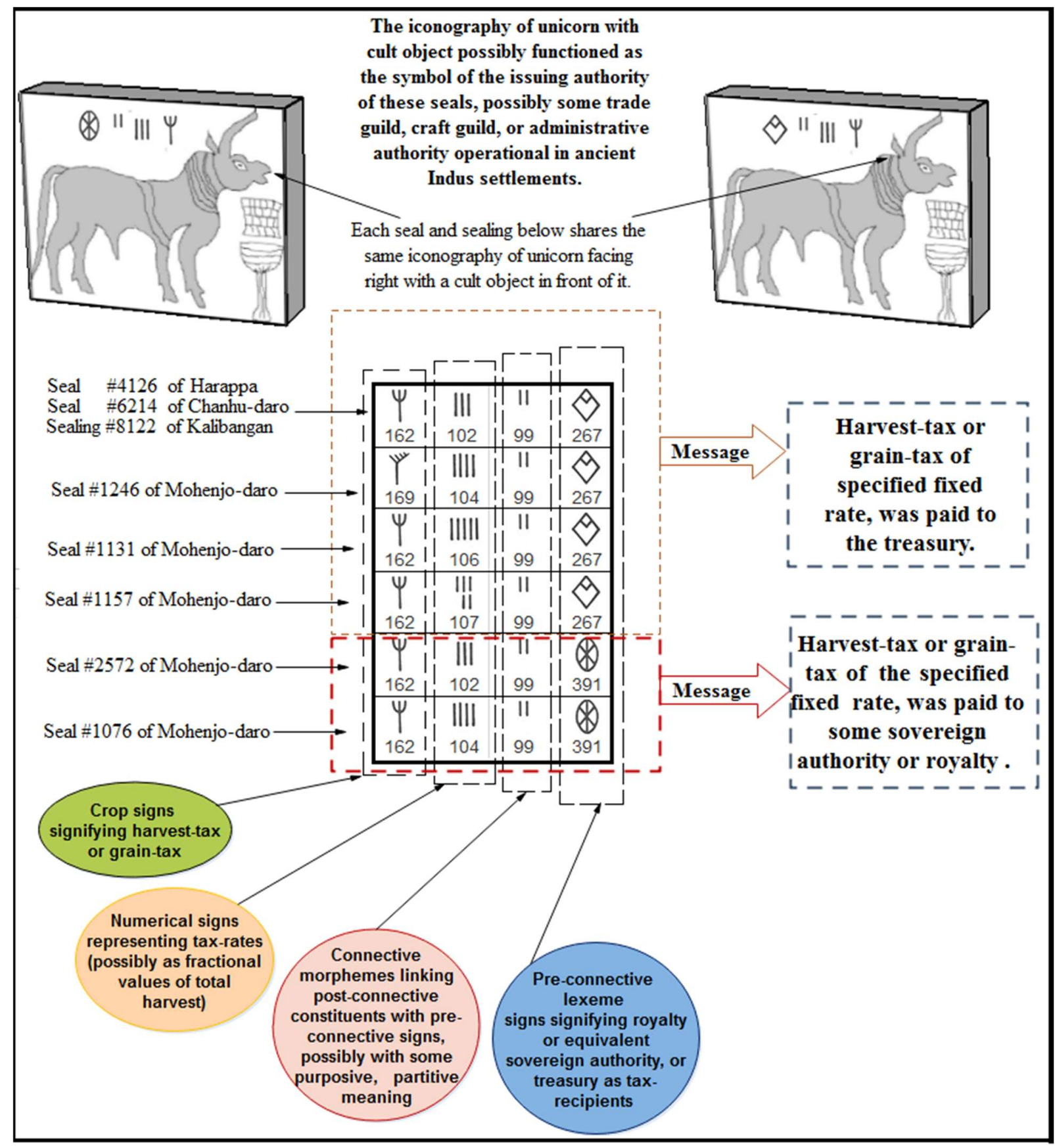

As depicted in the figure, by joining the meanings of the individual signs, we can quite effortlessly interpret the meaning of the inscriptions. According to my analysis, for the given set of inscriptions, the messages to be endorsed by the seals was that, "Some harvest-taxes or graintaxes (represented by the CROP-signs) were paid, using certain fixed rates (represented by the Numerals), to the treasury (represented by PCL-sign $\hat{\nabla}$ ) or to the royalty or equivalent oligarchic authorities (represented by PCL-sign $\bigotimes$ )". My future research will concentrate on finding more such "readings" of Indus inscriptions. 
Figures 1-5, and 7 have reused certain images partly or fully from my own previously published article Article_19.

\section{7: Conclusion}

Contrasted with the empirical nature of Article_19, which was based mainly on the scriptinternal and archaeological evidences, the current semantic analysis is more conjectural. However, the hypotheses made in this study have stemmed spontaneously from several archaeological, historical, structural and numismatic evidences, rather than from farfetched speculation. Below I shall discuss some important questions that are often asked while analysing Indus inscriptions.

\section{Which language(s) were encoded by Indus inscriptions:}

The "inhabitants of IVC were cosmopolitan, with multiple cultural groups living together in large regional urban centres like Harappa (Punjab), Mohenjo-daro (Sindh), Rakhigarhi (Haryana), Dholavira (Kutch/Gujarat), and Ganweriwala (Cholistan)" etc. (Shinde et. al, 2019). and several languages of different linguistic groups could have co-existed in different settlements in the one-million square-Kilometre span of IVC. Since the inscriptions on Indus seals and tablets had to convey meaning to many diverse speech communities, the logograms might have represented words from different languages using popular symbolisms. This means, if a particular linguistic community had proficiency in manufacturing a particular commodity (e.g. shellornaments or ivory objects), the words used in their native language for that commodity might have been popularized across IVC, and the logogram for that commodity might have been pronounced as that particular word. The graphemes used in that logogram might have symbolised the concept of the word in an ideographic way, or might have direct association to a linguistic word using metonymic symbolism. A good example of this concept is the Indian rupee sign ₹, which is based on the Devanagari letter " $₹ "$. While this ₹ logogram represents the Indian currency Rupee, and is pronounced as "rupaya", "rūpiyā", etc. by people speaking Hindi, Gujarati and many other North Indian languages, in Bengal people usually call this as "țākā". Interestingly this logogram ₹ is graphically associated with the first letter of the word "रुपया" (rupaya), which is in turn etymologically connected to the popular name of an ancient currency of India, the punch marked coins which were called "rūpa" and "rūpya" at least since Mauryan era (Mookerji, 1966:214). Thus, here an ancient word has generated a modern logogram, whereas another ancient word "tanka", attested from Puri Kushan coins (Chattopadhyay, 1967), which were 
prevalent in the Eastern India, have made the people of Bengal pronounce the Rupee logogram in a different way. The same could have happened to Indus logograms. Thus, identifying the language(s) encoded in the Indus inscriptions is a complex problem and needs more focussed prospective studies.

\section{Why the inscribed seals and tablets ceased to exist after the decline of IVC:}

Interestingly, the identification of Indus seals and tablets as "formalized data carriers" used by the administrative elites of IVC aptly explains the abrupt lull in the usage of Indus inscriptions, after the dissolution of the Indus urban centres. I can safely compare the demise of Indus script with the demise of the inscribed "Bala" taxation tablets of ancient Mesopotamia, which were integrally related to the centralized taxation system of Ur III, Neo-Sumerian state/empire, where tributary provinces had to pay fixed taxes rotationally to the central Mesopotamian state (Sharlach, 2004). But in the final years of the UR III ruler Ibbi-sin, when the superstructure of the UR state declined under the attack of the "Martu" tribes, the dismantling of the centralized taxation process also destined the "Bala" tablets to suddenly disappear (Kuhrt, 1995:70). I venture that in a similar way, when the decline of the Indus economico-political units happened (for yet unknown reasons), it wiped out the use of Indus seals, tablets and standardized weights in Indus valley locations. This is because the elite organizations that integrated the Indus economy using these tools possibly did not remain in power, even though the modus of intermunicipal or inter-guild trade system with its undergirding metrological system lived on for ages.

\section{Future scope:}

The future scope of this work involves an exploratory research regarding the semantics of many other signs. For example, whether the PF2-sign E, which resembles a harrow (Mahadevan, 2006), signified another agricultural term used in taxation in ancient India; whether the CM-signs harboured an implicit purposive or partitive meaning (its possibility arising from the polyvalent use of metrological symbols U' ' Z"F etc. as connective morphemes) while linking the semantic constituents - need to be researched in further detail. As briefly demonstrated in the previous section, many more inscriptions can be semantically interpreted, when more Indus signs get semantically analysed in future research. Also needed is investigating if the ancient scripts of North-western India, such as Kharoșthi or Brāhmi, bore any influence of the Indus script, the way the contemporary hieratic and hieroglyphic scripts of ancient Egypt bore substantial amount of influence on each other (Allen, 2000:6). A lot remains to be done to understand the proto-writing system used in IVC's bureaucracy, still eluding a comprehensive decipherment. This study ends with envisioning that thrilling possibility.

Figures 1-5, and 7 have reused certain images of Article_19. 


\section{Supplementary information}

Supplementary-File-1: An image of a news in an online Bengali News Daily (https://www.banglanews24.com/economics-business/news/bd/729151.details) to show the use of the ancient word "don" as a metrological noun.

\section{References}

Ahmed M. Ancient Pakistan - An archaeological history: volume IV: Harappan civilization theoretical and the abstract. Reidsville NC: Foursome Group, 2014.

Allchin B, Allchin R. The rise of civilization in India and Pakistan. Cambridge: Cambridge University Press; 1982.

Allen, J. P. (2000). Middle Egyptian: An introduction to the language and culture of hieroglyphs. Cambridge University Press.

Azarpay G. Sogdian painting: the pictorial epic in oriental art. Berkeley: University of California Press; 1981.

Belcher WR. Fish exploitation of the Baluchistan and Indus valley traditions: An ethnoarchaeological approach to the study of fish remains. 1998; Doctoral dissertation, University of Wisconsin-Madison.

Bhan, KK. Review of prehistoric cultures of Gujarat and need to develop accurate settlement gazetteer. International Symposium in India on Changing Perceptions of Japan in South Asia in the New Asian Era: The State of Japanese Studies in India and Other SAARC Countries. Kyoto, Japan: International Research Center for Japanese Studies; 2011.

Bhandarkar DR. Lectures on ancient Indian numismatics. Calcutta: University of Calcutta; 1921. Available from: https://archive.org

Bloomfield, M. (1899). Atharvaveda. KJ Trübner.

Bonta Steven. The Indus valley script: A new interpretation (A Semiologic approach showing distributional evidence and markedness as tools for interpreting patterned texts in the Harrapan corpus.). Penn. State University - Altoona College; 2010 
Brown, C P (1903). A Telugu-English dictionary (Vol. 2). Society for Promoting Christian Knowledge. Available at https://dsalsrv04.uchicago.edu/dictionaries/brown/

Budge EW. An Egyptian hieroglyphic dictionary: with an index of English words, king list, and geographical list with indexes, list of hieroglyphic characters, Coptic and Semitic alphabets, etc. London : John Murray, London; 1920. Available from: https://archive.org

Bühler G. On the origin of the Indian Brahma alphabet. Strassburg: K.J. Trübner; 1898. Available from: https://archive.org

Cameron GG. Persepolis treasury tablets. Chicago: University of Chicago Press; 1948. Available from: https://oi.uchicago.edu

Carey WA. dictionary of the Bengali language, Bengali-English. New Delhi: Asian Educational Services; 1981.

Chadwick J. The decipherment of Linear B. 2nd ed. Cambridge: Cambridge University Press; 1990.

Chattopadhyay, B. The age of the Kushānas: a numismatic study. Punthi Pustak; 1967.

Clegg J. The medieval church in manuscripts. Toronto, Buffalo: University of Toronto Press; 2003.

Clough B. A Sinhalese-English dictionary. Colombo: Wesleyan Mission Press; 1892.

Cruse D A (1986) Lexical semantics. Cambridge University Press: Cambridge.

In Kenoyer, J. M. (2017). Walking with the Unicorn.

Donkin RA. Beyond price: pearls and pearl-fishing: Origins to the age of discoveries. Philadelphia: American Philosophical Society; 1998.

Drekmeier C. Kingship and community in early India. Stanford: Stanford University Press; 1962.

Elliott JH. Beware the evil eye: The evil eye in the Bible and the ancient world. Vol. IV: Postbiblical Israel and early Christianity through late antiquity. Eugene, Oregon: Cascade Books; 2017.

Farmer S, Sproat R, Witzel M. The collapse of the Indus-script thesis: The myth of a literate Harappan civilization. Electronic Journal of Vedic Studies (EJVS). 2004; 11(2):19-57. 
Flood GD. An introduction to Hinduism. Cambridge: Cambridge University Press; 1996.

Francis P.Jr. Asia's maritime bead trade: $300 \mathrm{BC}$ to the present. Honolulu: University of Hawaii Press; 2002.

Frankel E, Teutsch BP. The encyclopedia of Jewish symbols. Northvale, NJ: Jason Aronson; 1992.

Frenez D (2017) Private Person or Public Persona? Use and Significance of Standard Indus Seals as Markers of Formal Socio-Economic Identities. In: Kenoyer, J. M. (2017). Walking with the Unicorn.

García JC., editor. Ancient Egyptian administration. Leiden; Boston: Brill; 2013.

Gardiner SA. Egyptian grammar: Being an introduction to the study of hieroglyphs. 3rd revised ed. Published on behalf of the Griffith Institute, Ashmolean Museum. Oxford University Press; 1969.

Gelb IJ. Makkan and Meluhbुha in early Mesopotamian sources. Revue d'Assyriologie et d'archéologie orientale. 1970 Jan 1; 64(1):1-8.

Ghosh S (2005, January). MONETIZATION AND EXCHANGE NETWORK IN EARLY HISTORIC BENGAL: A NOTE DEFINING CERTAIN PROBLEMS. In Proceedings of the Indian History Congress (Vol. 66, pp. 110-119). Indian History Congress.

Halloran JA. Sumerian lexicon: A dictionary guide to the ancient Sumerian language. Los Angeles: Logogram Publishing; 2006.

Harlan JR. The living fields: our agricultural heritage. Cambridge; New York: Cambridge University Press; 1998.

Howard-Carter T. Eye-Stones and pearls. In: Khalifa SH., Rice M., editors. Bahrain through the ages: The archaeology. London and New York: Routledge: 1986. p. 305-10.

Mukhopadhyay, B. A. "Interrogating Indus inscriptions to unravel their mechanisms of meaning conveyance." Palgrave Communications 5.1 (2019): 1-37.

Jarrige JF. Mehrgarh neolithic. Pragdhara. 2008;18:136-54. Available from: http://archaeology.up.nic.in/doc/mn_jfj.pdf 
Johns $\mathrm{CH}$. Babylonian and Assyrian laws, contracts, and letters. Union, NJ: The Lawbook Exchange, Ltd.; 1999.

Joshi JP, Parpola A. Corpus of Indus seals and inscriptions. I. Collections in India. In: Annales Academiae Scientiarum Fennicae. Series B 1987. Vol. 239. Helsinki: Suomalainen Tiedeakatemia; $1-375$.

Kenoyer JM. Ancient cities of the Indus valley civilization. American Institute of Pakistan Studies. Karachi: Oxford University Press; 1998.

Kenoyer JM. Early developments of art, symbol and technology in the Indus Valley tradition. IndoKoko-Kenkyu, Indian Archaeological Studies. 2001; 22:1-18.

Kenoyer JM. Eye beads from the Indus Tradition: Technology, style and chronology. Journal of Asian Civilizations. 2013; Dec 1;36(2):1.

Kenoyer JM. Measuring the Harappan world: insights into the Indus order and cosmology. In: Morley lain, Renfrew Colin, editors. The archaeology of measurement: comprehending heaven, earth and time in ancient societies. Cambridge; New York: Cambridge University Press; 2010. p. 106-122.

Kenoyer JM. The origin, context and function of the Indus script: Recent insights from Harappa. In: Osada T, Hase N, editors. Proceedings of the pre-symposium and the 7th ESCA Harvard-Kyoto Roundtable. Kyoto: Research Institute for Humanity and Nature; 2006:9-27.

Kittel F. A Kannada-English dictionary. 1st ed. Mangalore: Basel Mission Book and Tract Depository; 1894. Available from: https://archive.org.

Kosambi DD. An introduction to the study of Indian history. Bombay: Popular Prakashan; 1975.

Kosambi DD. Indian numismatics. New Delhi: Orient Longman; 1981. Available from: https://archive.org

Kuhrt A. The ancient Near East, c. 3000-330 BC. London and New York: Routledge; 1995.

Kula W. Measures and men. Princeton, NJ: Princeton University Press; 2014.

Macdonell AA, Keith AB. Vedic index of names and subjects.Vol. I London : John Murray, London; 1912a. Available from: https://archive.org

Macdonell AA, Keith AB. Vedic index of names and subjects.Vol. II Reprint. London : John Murray; London; 1912b. Available from: https://archive.org 
MacEachern M R (1999) Laryngeal Cooccurrence Restrictions. Garland Publishing: New York \& London.

Mahadevan I. Agricultural terms in the Indus script. Journal of Tamil Studies. 2006; Dec;70(1):6476.

Mahadevan I. Akam and puram: 'Address' signs of the Indus script. International Journal of Dravidian Linguistics. 2011;40(1);81-94.

Mahadevan I. Dravidian proof of the Indus script via the RigVeda: A case study. Bulletin of the Indus Research Center. Chennai: Roja Muthiah Research Library. 2014 Nov(4);37.

Mahadevan I. The Indus script: texts, concordance, and tables. Calcutta; Delhi: Archaeological Survey of India; 1977.

Mahadevan I. Towards a grammar of the Indus texts: Intelligible to the eye, if not to the ears. Tamil Civilization.1986; 4(3-4):15-30.

Marshall, J. (Ed.). (1931). Mohenjo-Daro and the Indus civilization: being an official account of archaeological excavations at Mohenjo-Daro carried out by the Government of India between the years 1922 and 1927 (Vol. 1). Asian Educational Services.

McIntosh J. The ancient Indus valley: new perspectives. Santa Barbara, Calif.: Abc-Clio; 2008.

McKoy B (2009). The Wings of Isis. John Hunt Publishing.

Monier-Williams M. A Sanskrit-English Dictionary Etymologically and Philologically Arranged: With Special Reference to Greek, Latin, Gothic, German, Anglo-Saxon, and Other Cognate IndoEuropean Languages. Clarendon Press; 1872. Available from: http://www.sanskrit-lexicon.unikoeln.de/scans/MW72Scan/2014/web/webtc2/index.php

Moorey PR. Ancient Mesopotamian materials and industries: the archaeological evidence. Winona Lake, Ind.: Eisenbrauns; 1999.

Mookerji R. Chandragupta Maurya and his times. Motilal Banarsidass Publ.; 1966.

Mukhopadhyay B A (2019). Interrogating Indus inscriptions to unravel their mechanisms of meaning conveyance. Palgrave Communications, 5(1), 73. 
Narain AK. Ganesa: a protohistory of the idea and the icon. In: Brown RL, editor. Ganesh: studies of an Asian god. Albany: SUNY Press; 1991

Nissen HJ., Damerow P, Englund RK. Archaic bookkeeping: early writing and techniques of economic administration in the ancient Near East. Trans Larsen P. Chicago, III.; London: University of Chicago Press; 1993.

Pal P, Richardson H. Art of Tibet: a catalogue of the Los Angeles county museum of art collection. Los Angeles, Calif.: The Museum; Berkeley: in association with University of California Press, 1983.

Parpola A, Pande BM, Koskikallio P, editors. Corpus of Indus seals and inscriptions: Mohenjo-daro and Harappa. 3: New material, untraced objects, and collections outside India and Pakistan. Helsinki: Suomalainen Tiedeakatemia; 2010.

Parpola A. Deciphering the Indus script. Cambridge: Cambridge University Press; 1994.

Parpola A. The roots of Hinduism: the early Aryans and the Indus civilization. New York: Oxford University Press; USA; 2015.

Parpola S, editor. Assyrian-English-Assyrian dictionary. Helsinki Winona Lake, Ind.: Neo-Assyrian Text Corpus Project; 2007.

Pitts-Taylor V., editor. Cultural encyclopedia of the body. [2 volumes]. Westport, Conn.; London: Greenwood Press; 2008.

Possehl GL. The Indus civilization: a contemporary perspective. Walnut Creek, CA: AltaMira Press; 2002.

Powell, Marvin A. 1990. Masse und Gewichte. In: Reallexikon der Assyriologie, Siebenter Band. Berlin - New York: de Gruyter 1987-1990, 457-516.

Prasad KD. Taxation in ancient India: From the earliest times up to the Guptas. Delhi: Mittal Publications; 1987.

Pruthi RK. The classical age. New Delhi: Discovery Publishing House; 2004.

Rainey AF. The El-Amarna correspondence: A new edition of the cuneiform letters from the site of El-Amarna based on collations of all extant tablets. Leiden: Brill; 2014.

Ranade MG. Rise of the Maratha power. Bombay: Punalekar \& Company; 1900. 
Rangarajan LN., editor. The Arthashastra. Delhi: Penguin Books India; 1992.

Rao SR. The decipherment of the Indus script. Bombay: Asia publishing house; 1982.

Roth M. T., editor. The Assyrian dictionary. P. Volume 12. Chicago: University of Chicago; 2005.

Reiner E., editor. The Assyrian dictionary: Š Volume 17. Part-iii. Chicago: University of Chicago; 1992.

Reiner E., editor. The Assyrian Dictionary: Volume 15-S. Chicago: University of Chicago; 1984.

Reis L C \& Hibbeln J R (2006) Cultural symbolism of fish and the psychotropic properties of omega3 fatty acids. Prostaglandins, Leukotrienes and Essential Fatty Acids, 75(4-5), 227-236.

Rogers RW, editor. Cuneiform parallels to the Old Testament. New York: Eaton \& Mains; 1912.

Rowe BM, Levine DP. A concise introduction to linguistics. 4th ed. London, New York: Routledge; 2016.

Sarkar KR. Public finance in ancient India. New Delhi: Abhinav Publications; 2003.

Sarma B. Vyasa's Mahabharatam. Kolkata: Academic Publishers; 2008.

Scurlock J. Sourcebook for ancient Mesopotamian medicine. Atlanta, Georgia: SBL Press; 2014.

Shah SG, Parpola A. Corpus of Indus seals and inscriptions. 2. Collections in Pakistan. In: Annales Academiae Scientiarum Fennicae. Series B 1991 (Vol. 240). Helsinki: Suomalainen Tiedeakatemia.

Shamasastry R. Kautilya's Arthaśāstra. Mysore: Wesleyan Mission Press; 1929. Available from: https://archive.org

Sharlach TM. Provincial taxation and the Ur III state. Boston: Brill; 2004.

Sircar DC. Indian epigraphical glossary. Delhi; Varanasi; Patna: Motilal Varanasi Dass; 1966.

Solé M J (1999) The phonetic basis of phonological structure: The role of aerodynamic factors. In: Proceedings of the Ist Congress of Experimental Phonetics: Tarragona, Spain, pp 77-94.

Tavernier J. Iranica in the Achaemenid period (ca. 550-330 BC): Lexicon of old Iranian proper names and loanwords, attested in non-Iranian texts. Leuven; Paris ; Dudley, MA : Peeters; 2007. Available from: https://archive.org 
Taylor J. Lilawati: Or a treatise on arithmetic and geometry by Bhāskara Āchārya. Trans. Taylor John. Bombay: Courier Press; 1816.

Thapar R. The Penguin history of early India: from the origins to AD 1300. London: Penguin; 2015. Turner RL. A comparative dictionary of the Indo-Aryan languages. Vol. I Delhi: Motilal Banarsidass Publisher; 1999.

University of Madras. Tamil lexicon. [Madras], University of Madras, 1924-1936. Available from: http://dsal.uchicago.edu/dictionaries/tamil-lex/

Vidale M. Growing in a Foreign World. For a history of the 'Meluhha Villages' in Mesopotamia in the 3rd Millennium BC. In: Melammu Symposia 4: Proceedings of the Fourth Annual Symposium of the Assyrian and Babylonian Intellectual Heritage Project. 2004. p. 261-280.

Wells BK, Andreas F. The archaeology and epigraphy of Indus writing. Oxford: Archaeopress; 2015.

Wells BK, Fuls A. Online Indus Writing Database. Berlin: 2006 Available from: http://caddy.igg.tuberlin.de/indus/welcome.htm. Accessed: May 1, 2016.

Wells BK. Epigraphic approaches to Indus writing. American School of Prehistoric Research Monograph. Oakville, CT: Oxbow Books; 2011.

Williams JH. Defining and measuring nature: The make of all things. San Rafael, CA: Morgan \& Claypool Publishers; 2014.

Witzel M. Aryan and non-Aryan Names in Vedic India. Data for the linguistic situation, c. 1900500 B.C. In: Bronkhorst J, Deshpande M, editors. Aryans and Non-Non-Aryans, Evidence, Interpretation and Ideology. Cambridge: Harvard Oriental Series, Opera Minora 3. 1999. 337-404. Available from: https://www.people.fas.harvard.edu

Witzel M. The languages of Harappa: Early linguistic data and the Indus civilization. Electronic Journal of Vedic Studies 2000 Feb;6:1-44.

Woods C. Visible language: the earliest writing systems. In: Woods C. Editor. Visible language: Inventions of writing in the ancient middle east and beyond. Chicago: The Oriental Institute of the University of Chicago, Chicago. 2011. p. 15-25. Available from: https://oi.uchicago.edu/sites/oi.uchicago.edu/files/uploads/shared/docs/oimp32.pdf.

Wright R P, Lentz D L, Beaubien H F, \& Kimbrough C K (2012) New evidence for jute (Corchorus capsularis L.) in the Indus civilization. Archaeological and Anthropological Sciences, 4(2), 137-143. 